\title{
An Expanding Earth A reply to two recent denial papers
}

\author{
Giancarlo Scalera (1)
}

(1) INGV - Roma, Via di Vigna Murata 605, Italy.

Corresponding author e-mail: giancarlo.scalera@ingv.it

Document type: Article.

Manuscript received 20 June 2019; accepted 11 August 2020; published online 13 October 2020; editorial responsibility and handling by R. Cirrincione.

\section{ABSTRACT}

In the March 2019 issue of the Rendiconti Online of the SGI, a geologist continued his attack on the theory of terrestrial expansion (Sudiro, 2019), this time focusing on the implications that paleomagnetic data, particularly the paleopoles, have as evidence for the expanding Earth concept. An initial more general publication on the subject by the same author appeared in the EGU History of the Earth Sciences journal in 2014 (Sudiro, 2014). The present paper demonstrates the inadequacy of many of the criticisms formulated in the above publications, making it clear that the expanding Earth is not an out-dated idea from the historical-scientific contingencies of the past, but instead a scientific concept that is very much alive and with very interesting future prospects. The evidential value of the paleopole data and catalogues is specifically defended here, together with the TPW and its link to the opening of the Pacific Ocean. The numerous lines of research that have emerged on the basis of expanding Earth are briefly described in a non-exhaustive review. The failure to recognise the expansion of celestial bodies as a phenomenon could be a contributing factor to the current state of crisis in Physics and Cosmology.

KEY WORDS: Expanding Earth, Geodynamics, Paleomagnetic data and catalogues, Earth expansion physics, History and philosophy of sciences.

\section{INTRODUCTION: HISTORY AND PSEUDOSCIENCE, OR SCIENCE AND PSEUDOHISTORY?}

In the March 2019 issue of the Rendiconti Online of the SGI, a paper (Sudiro, 2019; hereafter PS2) presented numerous criticisms of the theory of terrestrial expansion, focusing on the implications that paleomagnetic data, particularly the paleopoles, have as evidence for the expanding Earth concept. An earlier more general publication by the same author and on the same subject appeared in the EGU History of the Earth Sciences journal in 2014 (Sudiro, 2014; hereafter PS1). The author's intention is clearly to refute the idea of terrestrial expansion.

The quality of the criticism is low, and the self-styled role adopted by the critic in both publications is misleading. Presumably the author is a historian of science or aspires to become one. However, an incredibly sweeping assertion is made (in the title in PS1 and among the "key words" in PS2) that the expanding Earth (hereafter EE) concept is now part of an undefined pseudoscience, in an obvious partisan attempt to bias readers against EE. One can only wonder at the referees, whose role is to limit such excesses and impede the publication of offensive, unprofessional pronouncements.

Science remains science, even when practiced by minorities and involving marginal ideas. Otherwise we could have labelled as pseudoscience the work of biologists investigating cell biology, Lamarckian evolution, acquisition of characteristics, or internally driven evolution, while instead today these very areas are proving to be increasingly fertile (Lima-de-Faria, 1988; Gissis \& Jablonka, 2011; Jablonka \& Lamb, 1989, 2015; Chen et al., 2016; among many others). Likewise, those conceptualizing alternative cosmologies might be accused of anti-science, while everyone should instead be aware that the big-bang as a mathematical-physical model could be refuted at any time. Even its creator, Abbot George Lemaitre, was unequivocal about this, writing to the contemporary Pope to warn him against heralding the big-bang as a confirmation of the biblical fiat lux (Lambert, 2016).

Finally, we do not refer to Wegener's continental drift as pseudoscience, even though it was supplanted in the sixties by plate tectonics (Wegener, 1912, 1929). Nor will plate tectonics ever be defined as anti-science, neither today nor when it is inevitably supplanted by a new theory (which the present author believes will be the Expanding Earth). Cohorts of researchers have been at work on plate tectonics, generating an enormous quantity of data that will enable transition towards more accurate conceptions in the future. If it happened that EE emerged as the favourite, given time planetary expansion would in turn have to give way to new and more incisive ideas. The basic concept of expansion could remain valid, just as the centrality of the Sun remained valid in the transition from Copernican astronomy to the elliptical orbits of Kepler (later supplanted by the key role of the centre of gravity of the solar system, not to mention the motion of this centre of gravity). No true historian would ever be so disingenuous as to superficially label as pseudoscientific anything perceived as unusual or potentially threatening to the status quo.

The historical references in PS1 are incomplete and some are inappropriate. Roberto Mantovani (1854-1933) and Ott Christoph Hilgenberg (1896-1976, the first to use paleopoles to establish global paleogeography) were the 
two most important European contributors to the EE concept (Hilgenberg, 1933, 1974; Scalera \& Braun, 2003; Scalera, 2009a), but they are not even cited. Then in a list on page 136, Raymond Furon $(1935,1941)$ is cited as an advocate of EE. While Furon did quote the EE hypothesis in passing in a short paper in 1935 (in an eclectic way along with continental bridges) and again very briefly in the first edition of his book on paleogeography of 1941 (Mantovani had already presented his ideas in articles and talks at the Société Géologique de France; Scalera, 2009a), he subsequently dropped the quotation in later editions. Clearly, a few minor references do not qualify him as a contributor to the EE concept.

Any discussion of the history of science should be informed by an understanding of the subjects in question and the opinions of the researchers involved. The present author was incorrectly named among the scientists who do not believe in any form of subduction (PS1). I rectify this misconception by stating that I accept what geologists have directly observed in the field, which involves over- or underthrusting for a few tens of kilometres. This scientific perspective is clearly set out in Scalera (2010, 2012b). Instead I consider the postulated "large-scale" subductions, that are said to have erased "ribbons" of hundreds or even thousands of kilometres of oceanic crust, to be extreme hypothetical extrapolations. For example, in the case of the Pacific there is the exaggerated and radical suggestion that the lithosphere of an entire hemisphere was subducted into the terrestrial interior.

\section{MODERATISM, EXTREMISM, AND FINALLY REALISM: PULSATING EXPANSION}

The criticisms were directed in particular against the so-called "extremist" version of the EE theory, which involves a radius increase of about 100\% starting from the Triassic. Growing from around $3400 \mathrm{~km}$ to $6370 \mathrm{~km}$ in 250 million years would mean an annual growth rate of a few centimetres per year. Associating my name with those who sustain such rapid expansion rates is a complete travesty. The same error was made in the past by several expansionists, who attributed to me an expansion rate of more than two centimetres per year for the radius. However, I have clearly and repeatedly expressed full confidence in the results of spatial geodesy, which estimates current growth of the terrestrial radius in fractions of a millimetre per year (Scalera, 2012b; Shen, 2011, 2015), also confirmed by other evaluation methods (Xu et al., 2014, 2016, 2019). Minor corrections can result from neglected effects due to the expansion of the globe.

The current slow rate agrees with the ocean floor expansion rate (Müller et al., 1997; McElhinny \& McFadden, 2000), according to which we are presently at a minimum rate of spread, which in my interpretation is directly associated with a matching minimum in global tectonic activity. The apparent contradiction between rapid planetary dilation (about $3 \mathrm{~cm} /$ year from the Triassic to recent times) and the difficulty in detecting a centimetric expansion rate with geodetic tools (VLBI, GPS), is the result of our planet being in a phase of minimal tectonic activity. A $3 \mathrm{~cm} /$ year radius growth rate is therefore only an average, implying that if today the rate is less than one millimetre per year, in the epochs of geological past for which the map indicates maxima, the rate of growth must have been many centimetres per year. It is therefore naive and a logical error (in PS1, and also by the moderate expansionist Edwards, 2016, in his response to PS1) to associate the very low rate of modern expansion only with the moderate version of a slow EE. A Triassic Earth of almost half the current radius is equally possible, as supported by data from the Half Spreading Map of the Oceans (Müller et al., 1997; McElhinny \& McFadden, 2000) that suggest a pulsating expansion of the Earth over geological time, already hypothesized by the globe-maker Klaus Vogel (Vogel, 1984).

\section{MAPS DEPICTING CONFUSED INFORMATION}

Another defect (in PS1) are the maps reproduced or depicted in figures 1 and 2. The first shows the reconstruction of the Pacific by McCarthy (2003), attempting to demonstrate the vagueness of the match between opposite Pacific coasts, proposed in order to close the ocean in the Triassic. As already discussed in Scalera (2007), the paleontological arguments of McCarthy are accepted, and even those of Oakley Shields (1979) who adopts the same configuration (the paleontological data of McCarthy and Shields can also be fitted to my own configuration). However, McCarthy's figure is based on shapes of continents cut out from flat maps, with all the significant cartographic distortions that this implies. Furthermore, these distortions are in the opposite direction (from sphere to plane - equivalent to an ninfinite radius) to those that must necessarily be taken into account in variable-radius reconstructions (from sphere to sphere of smaller radius), and then effectively rendering the final results meaningless.

These sketches are not only worthless due to incorrect distortions, they also fail to show the consequences of these reconstructions for the opposite hemisphere: what happens to the Africa-Americas-Eurasia contacts? The mere cutting out of continental contours without taking the paleopoles into account achieves nothing. The clippings are irrelevant to variable radius cartography, which instead enables identification of a whole series of shape conformities in the Pacific, in turn confirmed by paleomagnetic data, all of which are solidly founded on a factual basis (Scalera, 1993). These conformities (Fig. 1) are supported by successful cartographic experiments (Scalera, 2018) that match all the similarities on an Earth of about $55 \%$ of the current radius, with important support of paleopole data from the GPMDB catalogue (Lock \& McElhinny, 1991; Florindo et al., 1994; Pisarevsky, 2005). In PS2 these results are overlooked or devalued, perhaps intentionally showing only incorrect representations that would be more readily rejected by average readers. A complete explanation of these similarities, and how they are recorded at unknown depth in the layers of the planet, does not yet exist. However, this should not exclude us from communicating their existence to those who will follow in our footsteps and hopefully be more able to fit them to a rational explanation. Science is a collective enterprise applicable not only in the present but over time, sometimes very long periods of time.

It is important to observe and assess the full set of conformities (Scalera, 1993) and to understand that their simple existence in a certain sense "crystallizes" the Pacific, challenging any hypotheses of large-scale subduction 

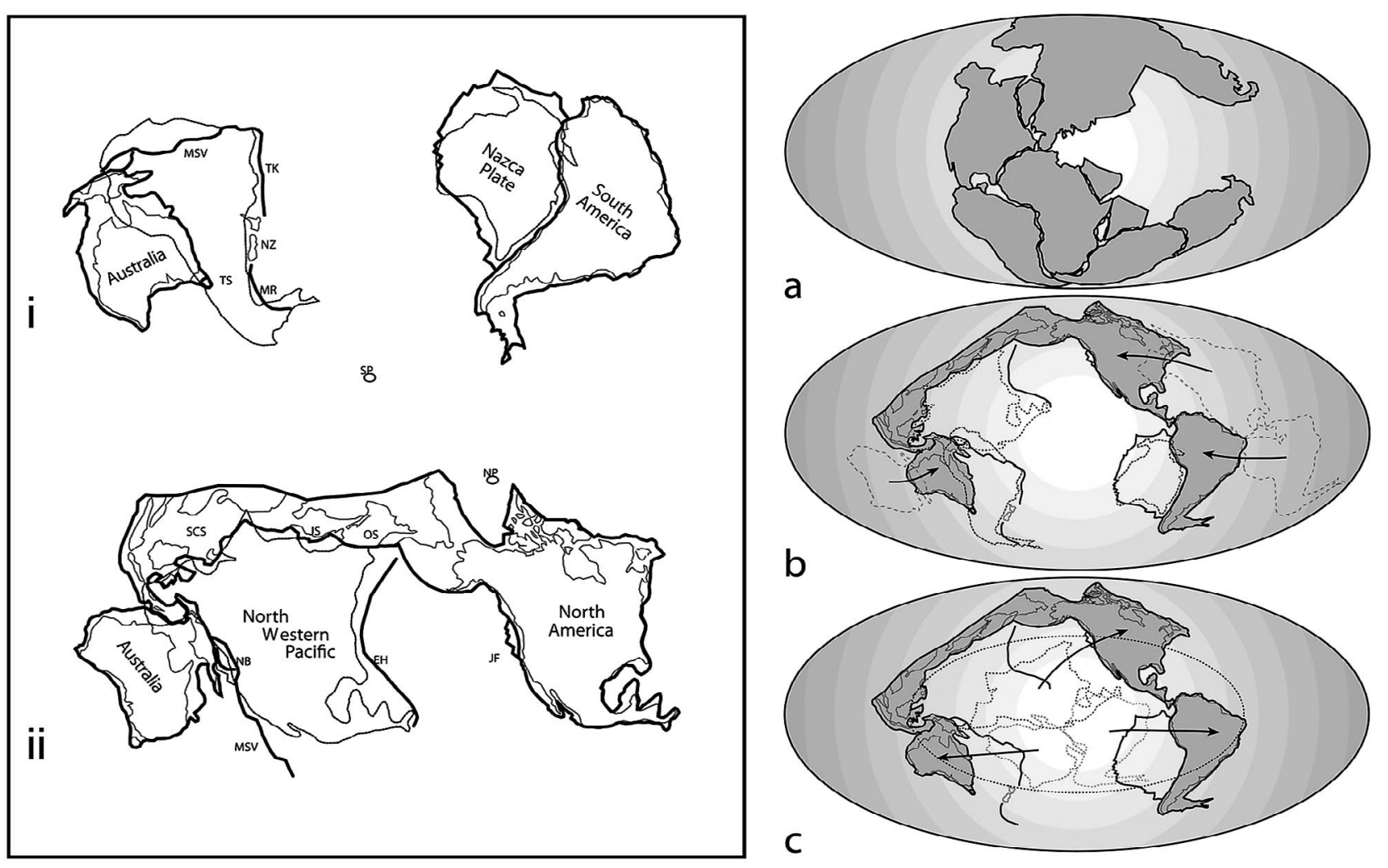

Fig. 1 - Basic cartographic experiments. Conformities in the Pacific hemisphere and interpretations. Left: continuous lines represent the contour of the coast. Bold lines represent the main tectonic discontinuities such as the margins of continental slopes, trenches, and expanding ridges. Also a bold line is an arbitrary boundary between Asia (not represented in the figure) and the arc and retro-arc areas of East Asia. i) - Conformities and continent-basin symmetry and vice versa in the southern hemisphere. South America corresponds in shape to the Tasman and Coral Sea basin, and Australia corresponds in form to the Nazca plate. ii) - Conformities and continent-basin symmetry and vice versa in the northern hemisphere. North America corresponds in form to the western North Pacific. The plate of Juan de Fuca corresponds to the ovoid plate ofNew Britain. SCS = South China Sea; JS = Sea of Japan; OS = Ochotsk Sea; EH = Emperor Hawaii volcanic chain; JF = Juan de Fuca plate; NB = The small New Britain ovoidal plate; MSV = Manus, Salomon, Vityaz trenches; TK = Tonga Kermadec trench; NZ = New Zealand; MR = Macquarie ridge; TS = Tasman Sea; NP = North Pole; SP = South Pole.On the right: a) - Reference Pangea. b) - All the conformities between continents and basins together with the (dashed) lines of Australia, Laurentia, and South America in the positions they assume in the reference Pangea. It is really impossible for these pairs of similarities to have been created if the route of the continents had followed the arrows that connect the positions of the continents in the Pangea (dashed lines) with their recent positions (grey). Conformities between basins and continents are on opposite sides of the destination hemisphere! c) - It is easy to understand that if the Earth had once been smaller than the modern Earth (the dotted ellipse, about half the radius of the Earth) before the breaking up of Pangea, then the continent shifts from Pangea (which covered the whole planet) towards modern positions would be essentially radial (with additional rototranslations), from starting positions that overlap and juxtapose all the conformities.

along its margins (hundreds or thousands of $\mathrm{km}$; but, as stated above, without excluding the well-documented overand under-thrusts of a few tens of $\mathrm{km}$ ) which would have erased the conformities. This is not the only factor that challenges subduction in the Pacific: there are also time and space correlations. The age distribution of the seafloor shows that the maximum age of all oceans is around $190 \mathrm{Ma}$. This seems problematic given that, according to plate tectonics, the Pacific should be contracting with subduction along its margins. Reflecting on the degrees of freedom allowed by possible different subduction rates on its opposite shores, the maximum age of the Pacific would be expected to be lesser or greater than that of the other oceans. Furthermore, the rate of expansion of the Pacific ridge is three to four times that of the Atlantic ridge, whereas a lower rate, only twice that of the Atlantic, would have been sufficient to enable observation of large portions of the Pacific Triassic or Paleozoic seafloor today (from 210 to $570 \mathrm{Ma}$ ). The rates of expansion and subduction of all the oceans appear (according to an undeclared implicit postulate of plate tectonics) finely tuned in a very particular manner that today paradoxically equalizes the maximum ages of exposed seafloors of all the oceans. Finally, as regards the reconstructions to smaller radii for the Upper Jurassic, the fragment of Jurassic marine crust adjacent to north-western Australia juxtaposes precisely with the Pacific Jurassic fragment. Taken together, this is not simply a clue but real proof of the expansion of the Earth and the almost synchronous beginning of ocean spread.

There are further details recognized right at the start of the history of plate tectonics but later rejected because they were embarrassing: the long Atlantic fracture zones were initially interpreted as indicators of kinematics between the Americas and Africa-Eurasia (Morgan, 1968). As soon as it was noticed that the trend for the Pacific fracture zones did not match expectations for the anticipated directions of hypothetical subductions, the fracture zones as kinematic indicators were substituted with the short transform faults. The fracture zones of the North Pacific are oriented in such a way as to link West Laurentia to 
the coasts and trenches of New Guinea, Salomon etc., precisely verifying the juxtapositions that variable radius cartography predicts taking into account the relative distortions on smaller globe diameters and GPMDB paleopole data. Again regarding transform faults, in PS1 at the bottom of page 137 and in Figure 4, the transform faults are erroneously identified with the fracture zones.

A further inaccuracy and source of confusion presented in PS1 is the map labelled B in figure 2. According to PS1 it is supposed to represent a map by Scalera and Maxlow, who as coauthors never published it or any other maps. It is instead only a detail from an elliptical map printed in Scalera (2007), which in PS1 is improperly enclosed in a circular boundary. The original map is an interpretation (in Scalera, 2007) of the Indian hemisphere in the Triassic with the Indian fragment positioned according to the paleopole data available at the time (with antipoles facing north), and with the western margin of India adjacent to Antarctica, which to date Maxlow has never accepted or represented in his elaborations (Maxlow, 2018). This displays an inability to distinguish the different ideas of the authors under discussion.

An additional major discrepancy is that PS2 (page 180) states that Scalera belongs to a group of researchers who believe that the Permian radius was equal to the primordial radius, with no increase in size occurring from the origin of the planet up to the Permian. While we are missing the necessary details to describe the progression of radius variation in the deepest geological time, some minor clues do already exist, and many years ago I already proposed reconstructions for times close to the Rodinia era (Scalera, $2009 b$ ). Several other researchers should probably also be excluded from the group invented in PS2.

\section{ANALOGY BETWEEN HYPOCENTRAL DISTRIBUTIONS OF THE ANDES AND MEDITERRANEAN}

If all the above is not sufficient to convince subduction proponents of the weakness of their hypothesis, it should be remembered that an effort was made to make subduction plausible for plate tectonics by adopting a partisan iconography. For example, the classic 2D diagrams of hypocentral patterns for vertical sections perpendicular to the central Andes (Fig. 2a) show regular patterns of immersion of hypocentres up to $300 \mathrm{~km}$ deep, with a tendency towards a lower slope in the lithosphere and a zone of absence of seismic foci between $350 \mathrm{~km}$ and $500 \mathrm{~km}$, offering the possibility for proposing a subduction surface.

However, abandoning these classic 2D sections and plotting 3D hypocentre maps not for thin sections but for very large volumes, several filaments of hypocentres emerge as thin funnels rather than a regular surface (Fig. 2b, 2c). A leading expert in global seismicity, Cliff Frohlich (2006), had already noticed these features while working in 2D, in this case on a section parallel to the Andes, from Colombia to Cape Horn, and he failed to explain the phenomenon. The 3D representation (created with the data extracted from the catalogue of seismic events relocated by Engdahl et al., 1998) is richer in information and resolves almost every filament as a distribution of hypocentres that starts from a very deep circumscribed area and then widens towards the surface like a plume of smoke from a chimney, all of them similar (Fig. 2c, 2d) to the distribution of hypocentres of the
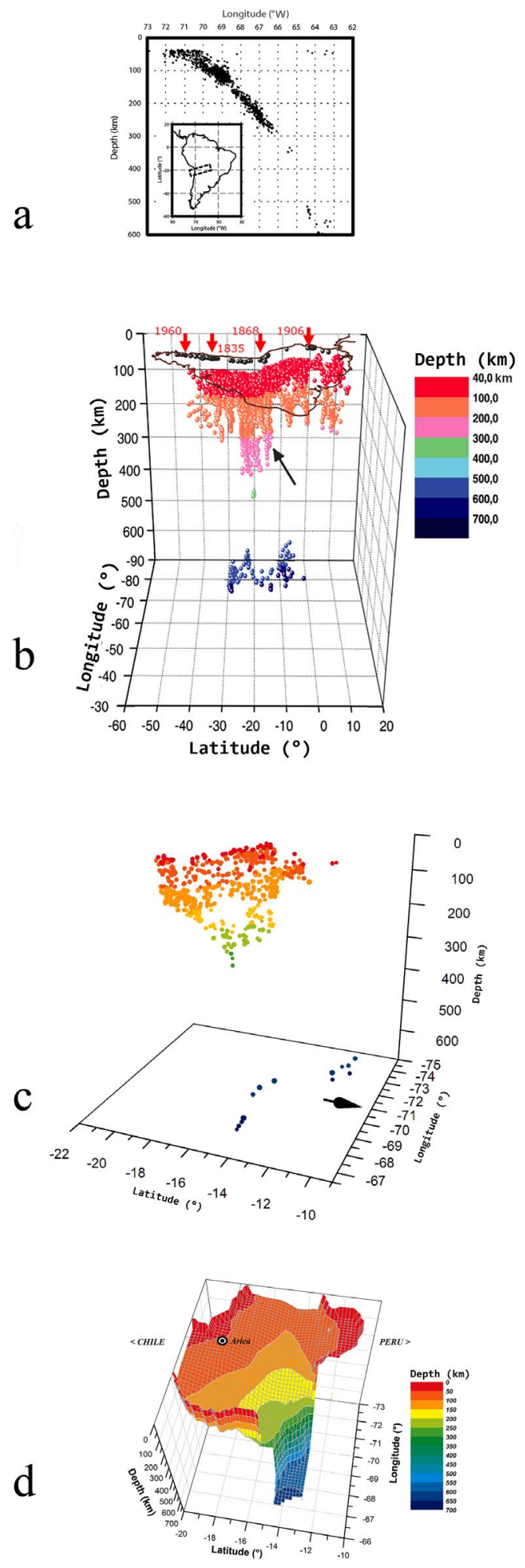

Fig. 2 - a) The misleading classical iconography of plate tectonics shows the distribution of the hypocentres in thin sections perpendicular to the Andean margin, inducing the reader to believe in the existence of subduction planes or surfaces. b) The reality shown in 3D is quite different, with a hypocentral distribution and filaments that widen towards the surface like plumes of smoke. c) A single filament (indicated with a black arrow in b) resembles a funnel, defining a sort of caldera where energy and materials are thrust upwards. d) The maximum spatial density surface of hypocentres is illustrated for the same filament. The funnel is similar to the one definable for earthquakes in the southern Tyrrhenian Sea (Scalera, 2008a, 2008b). In b) the red arrows and dates indicate earthquakes of magnitude $M>$ 8.4 that also constitute volcano-seismic correlation events. 
Calabro-Sicilian arch of the southern Tyrrhenian Sea (Scalera, 2008a, 2008b). The hypocentre distributions of the entire South American Wadati-Benioff area evidence a geodynamics unlike that of plate tectonics, with a flow towards the surface of energy and mantle materials. What is often interpreted in seismic tomographies as a subduction slab is actually a material denser than the mantle rising towards the surface. Major, extreme magnitude earthquakes provide crucial evidence for extrusion rather than material subduction. For example in Italy there was the opportunity to observe (Bianco, 2005) the shifting of the instantaneous terrestrial rotation axis in response to the great Sumatra earthquake of December 2004. The path of polar motion underwent a sudden shift away from the hypocentral zone that according to rational mechanics implies mass extrusion (Scalera, 2012) - in contradiction to the predictions of the predominant theory, which foresaw a displacement towards the hypocentre.

All this calls into question the compressional interpretation for both the orogenetic zones (although lateral expansions and compressions are interwoven in an inextricable interplay) and the Mediterranean region, for which instead it seems possible to infer continuous opening over various stages, at least since the Triassic (Chudinov, 1980; Scalera, 2005). Many European authors have tried to reconcile plate tectonics with the undeniable evidence of the opening of the Mediterranean and Tyrrhenian Seas (Moretti \& Guerra, 1997; Bell et al., 2004; Carminati et al., 2010; Lustrino et al., 2011; Scrocca et al., 2012). Their efforts at synthesis are certainly commendable and have been valuable for establishing the most varied information on diverse geodynamic aspects of the region. However, at the same time they also give the impression of extending to the Mediterranean the Tychonian type description that plate tectonics provides for our planet in general (i.e. a fusion of incompatible models: seafloor expansion and constant radius - see Scalera, 2012a; opening of Mediterranean basins and Africa-Eurasia convergence). A synthesis closer to actual geodynamics could be achieved by adopting orogenetic models in which the Wadati-Benioff zones are interpreted as material extrusion pathways from the mantle (examples in Scalera, 2007b, 2010, 2012b). In this regard it is important to note that, unlike the current mainstream view, EE generalizes the future of all the oceans, which are now more realistically seen to be opening up. Even the Mediterranean is freed of the bleak destiny predicted by the conventional model and will continue to offer up its marine treasures to whatever species succeed us and visit its marvellous shores.

The above observations also tend to deny the primarily compressive nature of orogens, which is corroborated by the prolongation of the expanding Pacific ridge (the segment adjacent to the oceanic plate of Cocos) into the Gulf of California and then along the mainland of Mexico, Arizona and California, to form an active orogen, and reappearing further north as Juan De Fuca (expanding) Ridge. This unification of orogens and dorsals helps to explain the apparent dissymmetry in the expansion of the North Pacific that is so problematic for opponents of EE (PS1, page 137).

\section{WHAT CAN BE INFERRED FROM PALEOMAGNETIC DATA}

The second text (PS2) calls into question the cognitive value of paleomagnetic data. Once again there is considerable confusion, with an attempt to define "the paleomagnetic method" (in absolute terms) - which would be able to test or refute the EE concept - the method proposed by Egyed in 1960. Egyed's triangulation method was debated at length in the last century (Carey, 1961; Egyed, 1961; Cox \& Doell, 1961a, 1961b; and many others later). The refutation of this method by Samuel Warren Carey still remains valid, defining it as impossible to apply due to the internal deformations of the continents being incompatible with the hypothesis of sampling sites located on a stable plate (Carey, 1961). I also tried to apply it, but with contradictory and inconclusive results (Scalera, 1991).

In PS2 there is an effort to demonstrate that the paths of the paleopoles of the individual continents as defined in literature are incompatible with the expanding Earth. However, the paths traced out in the figures are incorrectly conceived, completely overlooking the need to take variable radius cartography into account. Only by applying the appropriate laws of transformation (different laws for plates and for poles) for each epoch is it possible to obtain a valid result. This cannot be represented on a plane but in a hypersphere (an example in Scalera, 2001, for the path of the Indian fragment) with each pole on a sphere of radius appropriate for its age. The paths depicted in PS2 are therefore highly deformed, invalid, and only prove the author's superficial understanding of the problem.

There is no paleomagnetic method capable of proving expansion. There is only the good practice of observing the data in their simplicity and completeness, without applying mediated procedures (in other words, methods) that actually inhibit detailed assessment.

A case to point is the use of the Euler theorem of the single rotation pole, to which substantial resources have been committed for the compilation of tables for continent pairs, but with scarce cognitive results. These Euler angles are difficult to represent in a hypersphere and are only useful in relation to very short intervals of geological time (for example in Xu et al., 2019).

The section of Scalera (2018) setting out what is deductible for Africa (also see supplementary materials to the present paper), shows that it is sufficient to trace sampling sites, poles with confidence ellipses, and sitepole great-circle segments, to judge without interposed filters the situations, local and continental rotations, internal deformations, and mutual relationships of continents. To achieve this and make paleomagnetic catalogues useful, an appropriate selection of data (an example in Fig. 4) is obviously necessary, as is normal in any serious experiments in physics laboratories around the world.

The same paper (Scalera, 2018; partially reproduced here in the maps in Fig. 3; for the complete series of maps see the supplementary materials) offers further proof that the data should be applied directly and that the data selections are legitimate and well executed. Here the same selection of poles enables reconstruction of both the classical Pangea with all its exaggerations (Tethys Sea too vast, pre-Triassic Pacific crust more than hemispherical and today completely disappeared, India too isolated from Asia, etc.; Khan \& Tewari, 2017, among others) and all the globes of intermediate radius up to radiuses between 4000 and $3000 \mathrm{~km}$ (with conformities that progressively coincide). If the selections were incorrect or biased, then the reconstruction of Pangea with the modern radius 

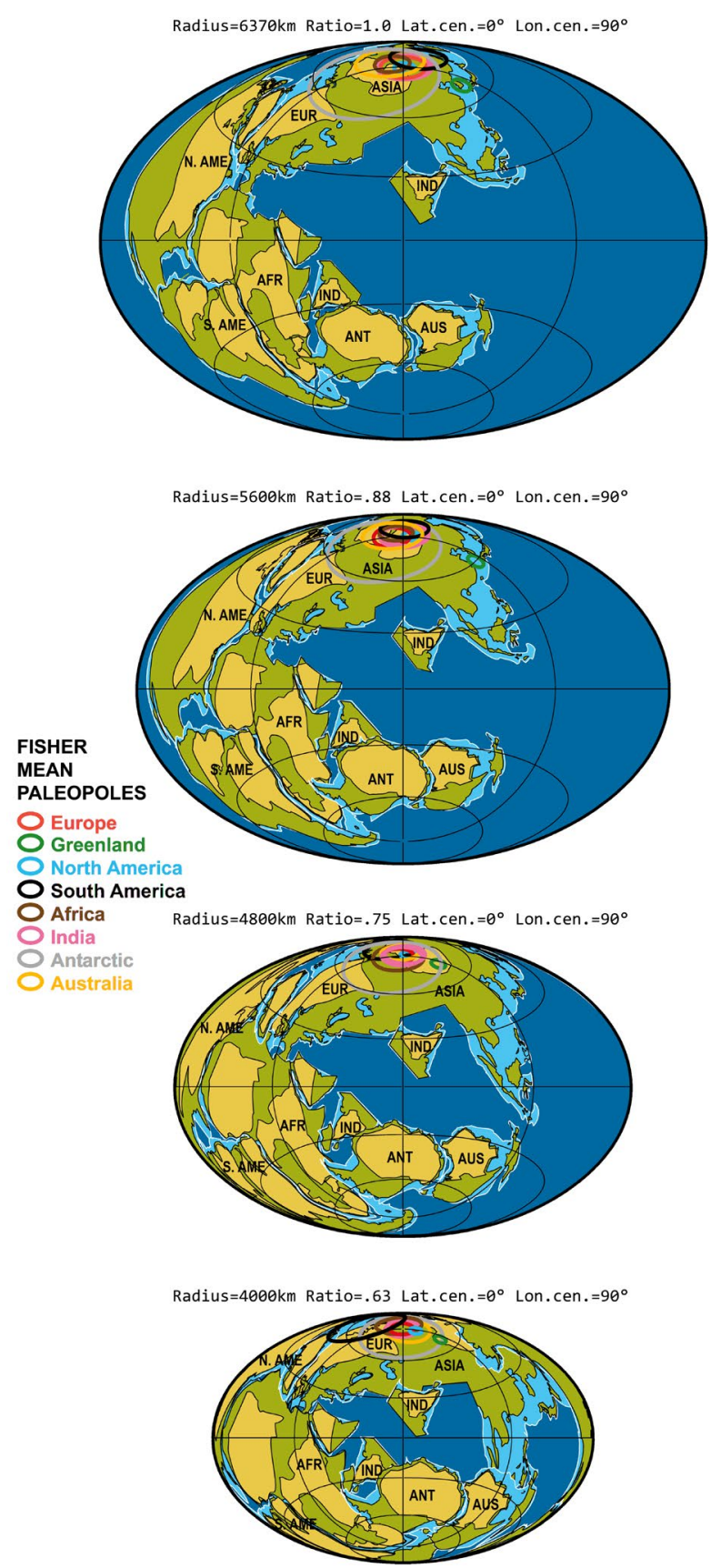

Radius $=3200 \mathrm{~km}$ Ratio $=.50$ Lat. cen.$=\theta^{\circ}$ Lon. cen.$=9 \theta^{\circ}$

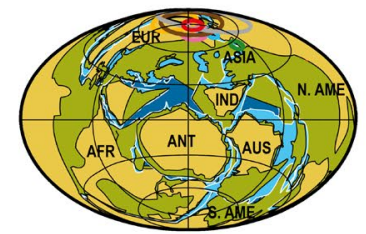

Fig. 3 - 5 of the 10 paleogeographic reconstructions performed (Scalera, 2018) for the Triassic, assisted by the GPMDB. From the first reconstruction (with a radius of $6370 \mathrm{~km}$ ) to the last (at 3200 $\mathrm{km}$ ) paleopoles were traced as Fisher averages (except for Africa and South America for which the only usable GPMDB pole is traced at $3200 \mathrm{~km}$; see Scalera 2018, and supplementary materials). The beige colour defines the Paleozoic shields; olive green the mainland of the current continents; and light blue the modern continental shelves. More details on this cartographic experiment, and the lists of GPMDB data used, can be found in the Supplementary Materials file accompanying this paper. would also be wrong, and the GPMDB catalogue would be useless.

Another instructive example of necessary data selection involves the global paleogeographic reconstruction of the Jurassic. The data for North America are very scattered with only a portion well grouped (Fig. 4) and selectable. An effort to reconstruct the reciprocal position of the continents that also takes into account the fragments of Jurassic crust on the Atlantic seafloor (Larson et al., 1985) shows that the poles selected for North America (or their Fisher averages) are shifted, with a counter-clockwise rotation, relative to those of Europe and Africa (Fig. 4). To explain this, plate tectonics has to invent the existence of objects that no longer exist in the Pacific (paleodorsal, oceanic paleoplates and their ancient modes of action on the western margin of America). In the expanding Earth framework nothing needs to be invented and the action is applied by what can still be observed today. A progressive expansion of the Pacific Jurassic crust, occurring initially in the northern hemisphere and interacting with the paleomargin of West America, can easily explain the rotation of the paleopoles (Fig. 4 and Fig. 5).

\section{MOVING FROM TWO CAUSES FOR A SINGLE FACT, TO ONE CAUSE FOR TWO FACTS}

PS2 lacks discussion of a very important phenomenon: the secular drift of the Earth's instantaneous rotation axis (PM) a few centimetres per year, extrapolated to about one geographic degree every million years. Over geological time this is known as the True Polar Wander (TPW) as revealed by statistical methods from paleomagnetic data (Besse \& Courtillot, 1991, 2002). Predictably, this represents a perfect prolongation of the segment defined by the astrogeodetic data from the last 150 years and known as PM (Scalera 2011). The slow drift of PM towards Canada has been explained by means of complicated flows of material in the mantle, in response to the isostatic imbalance produced by differential deglaciation of the continental platforms of Canada and Eurasia. However, this mechanism can only be extrapolated beyond the end of the last ice age by a few tens or perhaps hundreds of thousands of years, and with some difficulty. Beyond this time, this possible cause for PM is no longer applicable in association with TPW. Instead TPW can be traced back to times beyond 100 million years. Since glaciation can no longer be used to explain TPW in this period, this is solved by plate tectonics assuming a different cause from that for PM, hypothesizing changes in the geoid shape over geological time, possibly caused by convective motions in the mantle (another hypothetical process).

The EE scheme and its paleogeography resolves this implausible "double explanation" by providing a framework that does not separate PM from TPW, which share a single cause, based on a single global tectonic and geodynamic process (Fig. 5). It is sufficient to hypothesize that the Earth expands asymmetrically, growing and emplacing mass more rapidly in the Pacific hemisphere, the Pacific being larger than the other oceans and exhibiting a higher rate of seafloor expansion. The migration over geological time of the region of maximum emplacement of new crust and mass from the northern to the southern hemisphere is therefore able to account for TPW, its period of stasis around 50 million years (which corresponds to the transition to the equator of the 


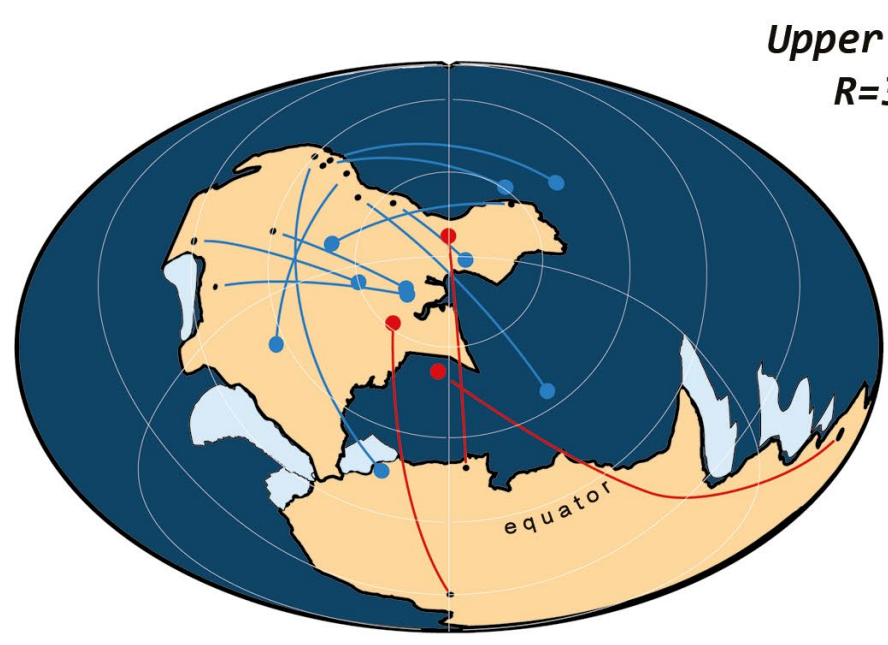

\section{Jurassic}
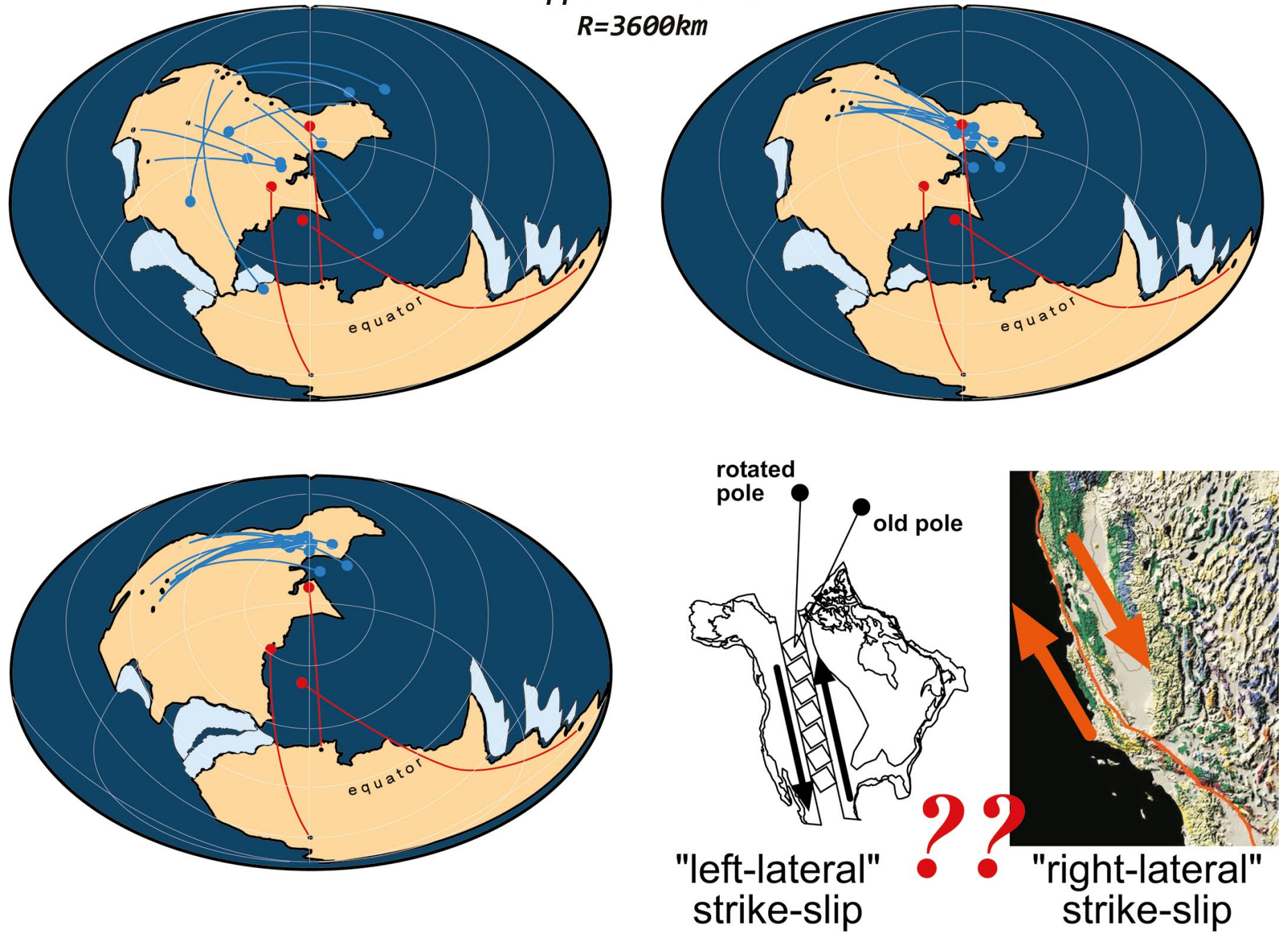

Fig. 4 - Problems with the paleopoles of the Upper Jurassic for Africa and Laurentia on a terrestrial globe of $3600 \mathrm{~km}$ radius. At the top left are the poles (in blue) of North America that have been discarded for obvious reasons. At the top right the selected North American poles that form a compact cluster, but which fail to provide a reconstruction coherent with the poles of Africa (in red). In fact the Atlantic Jurassic seafloor (in light blue; Larson et al., 1985) cannot be adequately juxtaposed. In the lower left-hand corner the Jurassic seafloor is well juxtaposed, observing a counter-clockwise rotation of the cluster of selected poles relative to the geographic pole and the contemporary African poles. At the bottom right it is shown that the rotation of these poles can be obtained by hypothesizing a left-hand lateral transcurrence acting on the western American Jurassic margin, opposite to the right-hand trascurrence that acts today in the San Andreas region. In the expanding Earth scheme this regime inversion can be explained by the occurrence of an initial Pacific expansion, starting in the northern hemisphere with southward migration of the maximum expansion point (currently at Nazca; see Fig. 5 below). The list of GPMDB data used can be found in the Supplementary Materials file accompanying this paper. Comparing this figure at $\mathrm{R}=3600 \mathrm{~km}$ with the same set of poles plotted at $\mathrm{R}=6373$ $\mathrm{km}$ in the Supplementary Materials file, provides an example in real data both of how paleopole distributions change in position relative to the continent, and changes in the same mutual pole distribution positions at different radii.

area of maximum expansion), and finally its acceleration towards its current position (Scalera, 2003), which extends to the PM of modern times. In this way TPW and PM once again become the same thing with the same cause.

The TPW should also be recalculated and represented in a hypersphere with each of its points at the appropriate radius and geological time. However, since the paths provided by Besse \& Courtillot $(1991,2002)$ are mediated by data from all the continents, they are probably very close to reality, at least as regards directions and motion inversion times.

In brief, the challenge to the cognitive value of paleomagnetic data is founded on inadequate, obsolete methods. The GPMDB data have already confirmed the coincidence of the Pacific conformities (the correct ones that $P S 1$ and $P S 2$ do not mention) on globes with radiuses near to half the modern one. The challenge also appears to ignore the most important results, which are the TPW, the geochronology of the ocean floor, and the paleogeography in EE. These support each other closely and jointly explain what instead in plate tectonics requires an embarrassing “double explanation" for TPW and PM.

Hundreds of researchers deserve our thanks for their painstaking work providing data for the construction of the GPMDB catalogue. The project was interrupted in 2004 due to lack of support from institutional sponsors, 


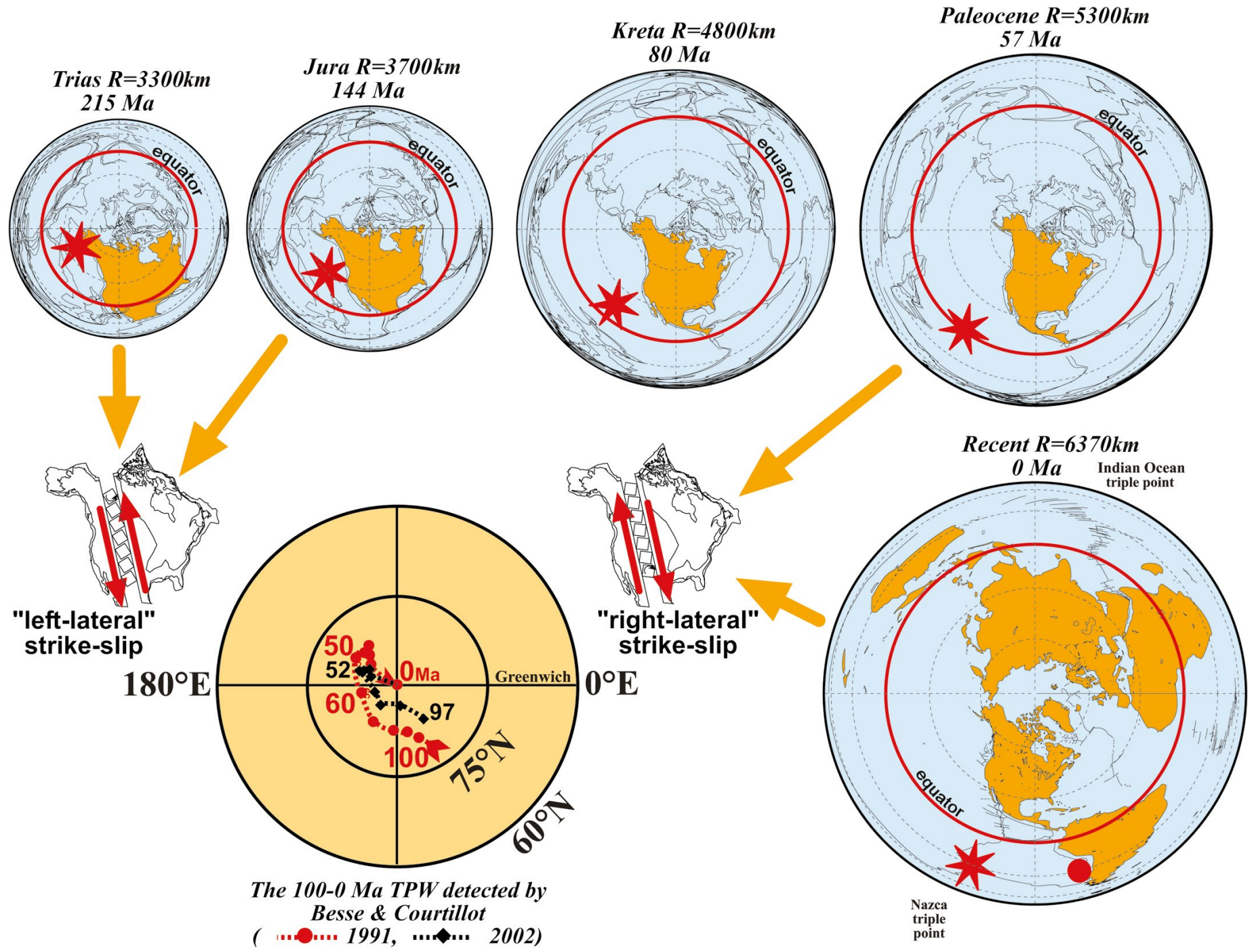

Fig. 5 - The region of maximum expansion of the Pacific (red star) was initially in the north during the Jurassic, and subsequently migrated southward across the equator to reach the Nazca region today. The evolution of the mutual position between expansion region and Western North American paleomargin may have resulted in the succession of the two opposite transcurrent regimes. The same migration towards the south has produced the path of the True Polar Wander (TPW; in the middle is the one determined in 1991 and 2002 by Besse \& Courtillot) with its period of stasis around $50 \mathrm{Ma}$ and subsequent reversal of direction. The unacceptable double explanation for TPW and PM from plate tectonics (see text), as resolved by the Expanding Earth remains (almost ironically) a duality, but this time acceptable, with the same phenomenon explaining two sets of data and paleomagnetic results.

and we should be united in our demands that it is resumed with the integration of 2005-2019 data. It is also worth noting that a second large catalogue of paleopoles is under construction for the Paleozoic (Veikkolainen et al., 2017) which we can look forward to applying in the future.

\section{THE CAUSES OF EXPANSION AND MODERN PHYSICS}

The following discussion will address only a few points in PS1 regarding the physical causes of expansion. Some of the proposed refutations are justified, like the continuous accretion of the planet due to dust and cosmic debris (the current rate of capture of cosmic matter is extremely low), or the hypothesis of a superdense core that slowly changed phase (excessively dense 3 or 4 billion years ago, and possibly resulting from a supernova explosion, which is too violent and disorderly an event to produce a system of planets with coplanar orbits, ordered according to the Titius-Bode law). Obviously it cannot be excluded that future knowledge might reopen such issues, especially as regards the possible effects of the periodic transition of the solar system through the galactic plane (every 30-40 million years), or other unforeseeable processes that could have acted on the dynamics of the primordial "Laplace nebula" and subsequent cosmogony of the solar system.

One very inadequate argument was the attempt to refute expansion resulting from an increase in mass. The abstract of PS1 states that, "according to the expansionists, scientists should really wait for some revolutionary discovery in fundamental physics that will explain all the unsolved mysteries of expanding Earth". The author appears to know or value only two major models of contemporary cosmology: the big-bang (adopted by the majority and dear to conservatives due to its analogy with 
the biblical narrative), and the steady state (sustained by a minority but certainly not defined as pseudoscience, dear to the more secular because it conserves the status quo). An alternative model that might surpass the two mentioned above for good reasons (Scalera, 1988) is completely overlooked. Its antique origins were vaguely expressed by Isaac Newton (1643-1727) and John Bernoulli (1667-1748), later finding a more coherent proponent in Yarkovsky (1888). The concept of ether in motion, converging towards the celestial bodies, gives a glimpse of a much more evolutionary and mobilistic cosmology at infinite levels (Fig. 6) compared to the big-bang and steady state models (Scalera, 2018). Only a first incomplete step has been made in this direction by Dirac with his "multiplicative creation" (Dirac, 1937). A refutation of the possibility of new

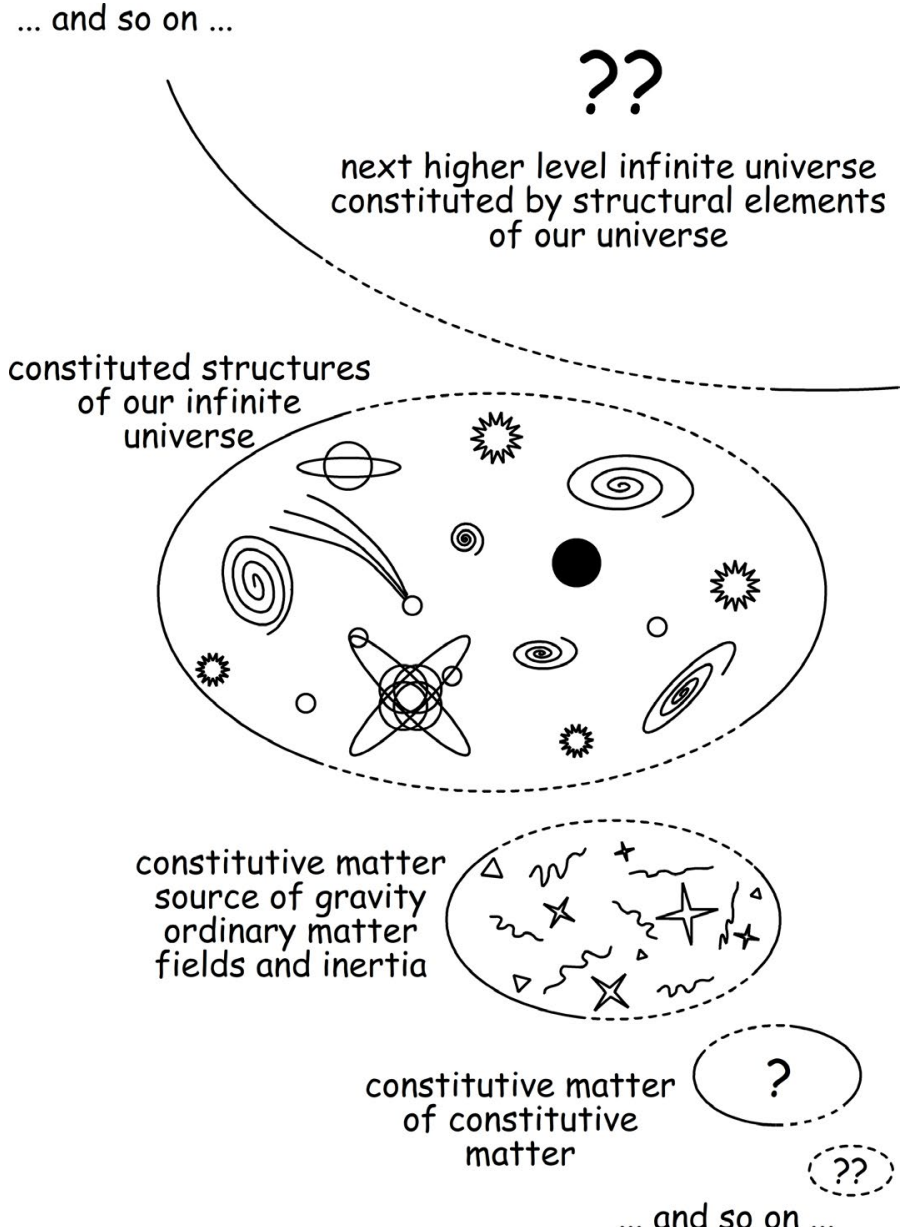

Fig. 6 - An infinite and infinite levels evolutionary universe derived from the Earth Sciences. Each level builds up and evolves by feeding on the lower levels. The universe that we can now observe directly or indirectly, from large-scale cosmic structures to microphysics, is emerging at the expense of a constitutive material, which can be observed due to the expansion of celestial bodies. This impalpable matter is being formed by drawing on lower order constituent material, and so on. Our ordinary matter and its structures (micro and macro) are constituent matter, or "ether", for a universe of higher order of spatial and temporal scales immeasurably greater than ours. All universes are supplied from lower order structures, together forming a continuum in mutual evolution. The boundaries between one universe level and the next of major or minor order are not well defined. For example, the micro and macro boundaries of our universe only derive from our current ability to build devices and observational experiments, and are therefore in progressive expansion. ordinary matter forming inside planets (at the expense of ether) on the basis that an antineutrino must be emitted to form a neutron is inadequate (PS1, page 142). Physicists are are still far from understanding materiogenesis, today discussing in vague terms a "primordial soup" in which quarks or more elementary particles could aggregate the particles we know. An alternative process of materiogenesis, starting from ether and occurring in the central region of planetary cores, raises implications as yet unexplored.

It must be reiterated and clarified that the Earth expanding due to known physical causes, like for example crystalline phase changes or other contingent time-limited phenomena, would not upset mainstream cosmology. Instead, in the case of expansion by materiogenesis, the current cosmology developed from the increasingly complex physical-mathematical model of the big-bang would have to be abandoned, because a model that does not take into account the macroscopic phenomenon of expansion of heavenly bodies could not be considered as valid. Doubts and reservations about the big-bang model have been slowly accumulating. There is the very striking fact that the model fails to equalize its own energy balance (detected mass and energy representing only 5\%, while the residual and never observed "dark matter and energy" constitute $95 \%$ ). There are also numerous phenomena that fall outside its scope, and the list continues to grow (Lerner, 1992; López-Corredoira, 2019). It is therefore legitimate to ask whether a model in which celestial bodies grow by feeding on an ocean of impalpable substance, slowly changing its characteristics due to this transfer, is also able to explain the redshift-distance law that was never accepted as proof of true recession of galaxies even by its discoverer, Edwin Hubble (Soares, 2018). This new path indicated by $\mathrm{EE}$ is unexplored and difficult, without any guarantees of success, but certainly worthy of investigation.

However, indications that something anomalous is occurring in planetary cores are already available. The Earth itself is a test case providing indications for useful experiments in fundamental physics. Some have already been carried out, others are ongoing in both small and large scale physics. In small scale physics there have been experiments attempting to reveal a privileged Lorentz' reference system, as proposed by a group of the Catania INFN (Consoli et al., 2014), and studies conducted at the Flinders University of Adelaide in Australia (Cahill, 2009). Ether has been a stone-guest of science for a long time and even initial deniers were and are now forced to take it seriously (Kostro, 2001; see also the text of Einstein's lecture of 1922 dedicated to this physical entity). Numerous theoretical physicists are actively working to the gravitational field as an emerging phenomenon from the flow of a thin medium possibly converging towards all masses. One researcher, Grigory Volovik (2001), simulated gravitational fields in the laboratory using superfluids in already famous experiments. One of the most recent winners of the Nobel in physics, Frank Wilczek (2008), confidently describes ether from this contemporary perspective: "What appears to our eyes as empty space is revealed to our minds as a complex medium full of spontaneous activity". Some scientific popularisers may not yet have noticed, but the ancient problem dating back to the beginnings of philosophy (De Paoli, 1988; Kragh \& Overduin, 2014; Consoli \& Pluchino, 2015) of the existence or non-existence of vacuum has been solved. The vacuum of paradoxes and unacceptable action at a 
distance has been filled for some decades now, and contact interactions are again necessary. Research is shifting to the nature and properties of the medium, with planetary expansion indicating a path for investigation.

Today professionals generally admit to a state of crisis in the foundations of physics and cosmology, and a need for radical change is clearly foreseen (for example in Hossenfelder, 2019; Tonelli, 2019; among several others). But while there is awareness that some theoretical and experimental paths are becoming closed or problematic, there is also a failure to realize that the innovations necessary for change might not come from the sky but from what "large scale physics" has already deduced for the interior of the Earth in experiments already carried out. Starting from the conformities of the Pacific, a chain of logical reasoning suggests that some fundamental observations should fall outside the expectations of global geophysics for the terrestrial interior. A glimpse of this comes from the very refined experiments in progress both in Italy, Borexino at the Gran Sasso, and in Japan, KamLAND on the island of Honshu, set up to measure the radiogenic heat of the Earth (results published in the INGV journal Annals of Geophysics: Borexino collaboration, 2017; Shimizu, 2017). As predicted in the materiogenesis version of terrestrial expansion, there are some problems.

The value of total terrestrial heat flow assessed from data recorded in mines and tunnels is 45-47 TW (Terawatt $=10^{12}$ Watt $)$. This value should represent the sum of the radiogenic heat measured by large scale physics (best values: KamLAND 8-16 TW; Borexino 18-28 TW) with the residual primal heat (estimated between 5 TW and $15 \mathrm{TW}$ ). The problems for traditional concepts are immediately obvious: the terrestrial radiogenic heat flux predicted by the geodynamic model with convective cells $(33 \pm 04 \mathrm{TW})$ is not confirmed. Even taking the average Borexino value of $\approx 23 \mathrm{TW}$, we need to add a primitive heat value from the low end of its estimate due to the greater dissipation caused by convective motions, but even conservatively adding its average of $\approx 10 \mathrm{TW}$ we would be far from a total of 45 TW. Important geophysicists (Anderson, 2009; Fiorentini et al., 2007; among others) resolve the problem by not taking the averages but the highest values permitted within standard deviations, but this solution appears somewhat forced. The need for identification of an unknown source of terrestrial heat therefore persists, calling for an explanation. It is obvious and natural to wonder whether the unknown heat source is linked to the unknown physical phenomenon that drives terrestrial expansion. It should be considered that the radiogenic heat predicted by the two cosmochemical and geochemical models without convection $(\approx 11$ TW and $\approx 20$ TW respectively) is well within or only partially exceeded by the measurements of large scale experiments. It is therefore legitimate to ask whether some of the neutrinos detected in Borexino and KamLAND might be produced by materiogenesis, and finally whether some of the unexplained heat flow is not due to an increase in the kinetic (thermal) energy of the materials in the Earth's core coming from radioactive decay, but instead caused by the convergence and transformation of ether.

Two more observations further support the legitimacy of the ideas set out above: A) discussion about the missing heat source is underway, and an alternative proposal is the existence of a nuclear fission reaction generated by gravity migration of heavy radioactive elements towards the region near the terrestrial centre (Herndon, 1993). However, this would generate no more than 5-7 TW, and the idea is rejected by many for various reasons, also geochemical (Degueldre \& Fiorina, 2016). It is worth adding that the everdecreasing force of gravity towards the geocentre would not favour the hypothesized migration and concentration; B) there are some other unresolved problems regarding the Earth's core, including thermal conductivity, heat fluxes, maintenance of convective motions, etc. (an excellent review in Sumner, 2015). This demonstrates that the investigation of the state and geodynamics of the internal and external core is still wide open, and that the EE and its causes could play a role.

If we assume materiogenesis to be true, we should expect even more macroscopic effects on large-scale structures of the universe. The problems posed by galaxies are naturally linked to materiogenesis, both in terms of shape and rotation speed, problems that a "general" theory of the universe - as general relativity is considered by many - should explain but fails to do so due to intrinsic limits to its rather overvalued generality.

\section{TERRESTRIAL GRAVITY: INCREASING OR DECREASING?}

The present discussion will not add much on the subject of the consequences of expansion on terrestrial surface gravity $\boldsymbol{g}$ (topic covered in PS1). Paradoxically, very large effects would be expected for the version with phase changes, towards more open crystalline lattices, of the Earth's core and mantle, with a decrease in gravity as the surface moves away from the centre (the force of gravity acting on us is equivalent to force caused by the mass contained in the geocentric sphere tangent to our position, as if it were all concentrated in the geocentre). Instead, caution is required about the effects of materiogenesis on $g$. A mass increase of the entire planet can be compensated in various ways by differentiation of core and mantle, and consequently different velocities of removal of the surface by the centre. The present author has no definitive solutions to offer. However, some researchers (called "enthusiasts" in PS2) converge from different starting points towards increasing gravity over time that eliminated the most corpulent animals (Hurrell, 2012; Strutinsky, 2016) and shaped the evolution of the cardio-circulatory system (Mardfar, 2012). Finally, the bibliographical references cited in PS1 and PS2 fail to mention the excellent seminal paper by a student of S. W. Carey, the oil geologist John Davidson, who I hope will return to this subject with further contributions to the expanding Earth concept (Davidson, 1994).

On the other hand, as far as the universal gravitational constant $G$ is concerned, at the moment nothing definitive can be said, at least not until a new more detailed cosmology has been built conceptually and mathematically, taking into account the indications provided by the EE. Nearly half of recent Kragh's (2016) book on the history of debate about "varying gravity" was dedicated to the EE.

\section{EXPANDING EARTH A STEP AHEAD OF MOBILISM}

It is stated at another point in PS1 (page 136) that the EE can be classified as fixism. From the beginning of my work in this research field I have made abundantly 
clear that this is not true. My old and simple cartographic experiment (Scalera, 1995) definitively demonstrated the point.

Here the original experiment is repeated with greater rigor (Fig. 7): applying to the modern radius Earth an operation decreasing the radius, leaving the geographical coordinates of the continental geometric barycentres fixed. On the resulting globe of approximately halved radius the continents would not aggregate into a Pangea supercontinent without additional displacements and rotations. There is also a large overlap in the Mediterranean (marked like the others in dark grey) while the Pacific remains open. The expansion did not occur homogeneously with spherical symmetry, but with more or less active zones: a maximum on the Pacific and a minimum on the opposite hemisphere. Tangential rototranslations would be necessary relative to a deep substrate, hence the definition of mobilism. The rototranslation of Australia, Antarctica, and India need to be particularly marked in order to comply with the orientations indicated by the respective paleopoles.

Wegener's (1912, 1929) continental drift and the subsequent plate tectonics were two successive steps in the direction of mobilism, and planetary expansion constitutes a further step ahead towards a more general mobilism not only tangential but also radial, on a hypersphere.

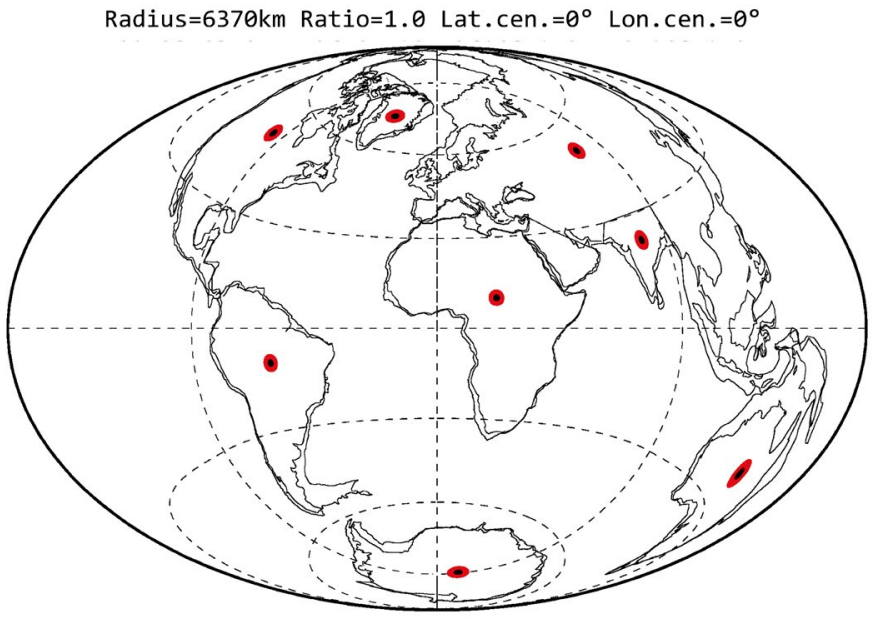

Radius $=3600 \mathrm{~km}$ Ratio $=.57$ Lat. cen. $=0^{\circ}$ Lon. cen.$=0^{\circ}$

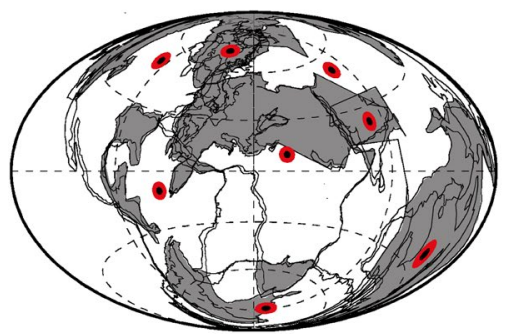

Fig. 7 - The pure radius decrease operation is applied to the Earth of current radius (above), leaving the geographic coordinates of the continental barycentre (in red) unchanged. On the resulting globe of $3600 \mathrm{~km}$ radius (below) the continents do not form a supercontinent Pangea without imposing additional displacements and rotations. A large overlap is present in the Mediterranean (marked like the others in dark grey) while the Pacific remains open. So the expansion does not progress homogeneously with spherical symmetry, but with zones of lesser and greater intensity, with a maximum on the Pacific and a minimum on the opposite hemisphere.

\section{OPEN PROBLEMS AND FUTURE LINES OF RESEARCH- UNEXPLORED HORIZONS}

This paper cannot extend to all the points mentioned in PS1 and PS2, but it is worth noting that many of the points (for example: paleontological distributions, epicontinental seas, etc.) are issues that are still very much under discussion by everyone, even proponents of plate tectonics. Biology still has problems explaining speciation, let alone how species are distributed and territorially separated: an extremely complex process influenced by many factors like geotectonics, climate, interdependence and compatibility or otherwise of different species, for both animals and plants and their interactions.

This final section will briefly address some issues not discussed in PS1 and PS2, but which are in any case relevant to better understand the general applicability of the expansion concept, providing specific solutions in various scientific fields, from a list that is almost certainly destined to grow over time, and providing pointers for further research and analysis.

In paleoclimatology, EE proposes a solution to the anomalous paleotemperatures detected when moving back through geological time. The solution is based on the minor variation in size of the continental shelves compared to the total surface variation of the entire globe. The result is an ever greater extension of the Arctic (and Antarctic) polar circle - from deep geological time toward the present - compared to almost unchanged sizes of the continents, with an effect on paleotemperature trends as a function of latitude through geological time (Crowley \& Zachos, 2000). The distortion relative to the modern curve is increasingly marked moving towards more ancient periods (see the specific figure in Scalera, 2003, retraced from Crowley \& Zachos, 2000). Erroneously assuming that the radius of the Earth was constant would lead to the climate of earlier eras appearing to be abnormally mild, presenting fossils of non-glacial flora and fauna within a modern size polar circle. The existence of a uniformly warm climate during the Meso-Cenozoic is an unsolved problem of paleoclimatology.

For science dealing with sea levels, it can easily be demonstrated (Scalera, 2015) that an expanding globe produces more than negligible effects due to differences in the curvatures of oceanic and continental surfaces. The continents tend not to adapt immediately or completely to the decreasing curvature of the globe, and they lose excess altitude - caused by this lack of adaptation - both by erosion and isostatic subsidence. The value of apparent sea level variation due to the ignored expansion falls within the same order of magnitude as the other factors already taken into account for the assessment of sea levels (Scalera, 2015). A future line of research would be the relevance of this term for current global sea rise estimates, and its introduction into the equations.

Other logical connections could be formulated for the thorny issue of direct and retrograde metamorphism and HP-UHP along the orogens. The mere existence of earthquakes in the fragile part of the lithosphere (a few tens of kilometres deep) conflicts with the presumed existence of a complicated "two-way subduction channel" - a low viscosity channel that is thought to bring subducted and metamorphosed materials back to the surface. Earthquakes are the most important circumstantial evidence of conservation, accumulation, and then local 
release of deviatoric stress, which can be a cause of local overpressure (Mancktelow, 1995, 2008). The possibility that exhumed HP-UHP lenticular fragments could be a mechanical product of large seismic events at depths not exceeding a few tens of kilometres should therefore be considered. A model of uplifting and evolution of a fold-belt is in agreement with the high-speed anomalies of the $\mathrm{P}$ and $\mathrm{S}$ waves detected tomographically below most orogens and arcs. The topographical heights obtainable are consistent with the volume increase values associated with the main mineralogical phase transitions. In this perspective, a discontinuous upward movement of mantle materials can be linked to the observed discontinuous evolution of the orogens, and to the widespread observation of raised coastal terraces (Scalera, 2010). These are interesting lines of research for the future, which could be associated with the concepts developed for mountain evolution by Ollier \& Pain $(2000,2019)$. These two authors show that folding occurred prior to uplifting and that the latter occurred only in the past few million years for the majority of mountain systems - the so-called "neotectonic period" (NP). The contradiction of plate tectonics is evident: the Andes, for example, interpreted as the compressive product of a subduction underway from before Mesozoic times, instead appear to have been raised over a much shorter time Upper Miocene - Plio-Pleistocene (Coltorti \& Ollier, 1999).

The NP was bluntly rejected by advocates of plate tectonics (see the harsh criticism by Molnar, 2007, and the firm reply from Ollier \& Pain, 2019). In synergy with EE, recognizing the existence of the NP implies that other NPs may have existed in other more ancient segments of the geological past, assuming the very unlikely uniqueness of this enhanced period of mountain uplift. New lines of research could then be established to identify previous NPs, and verify if the minimum spreading rate (see the Half Spreading Map of the Oceans; Müller et al., 1997; McElhinny \& McFadden, 2000) and consequent minimum expansion are related to the uplifting of fold belts and mountain ranges in general. It could be reasoned that during the phases of rapid expansion the material emerging from deep inside the planet is accommodated in "chambers", which also expand. During phases of minimum expansion the "chambers" do not accommodate the mass flow in ascent, and consequently it extrudes towards the surface causing the observed uplift and enhanced periods of mountain building. The details of this slow process of pulsation (prefigured on a different basis and timescale by the late Forese Carlo Wezel, 1988, 1992, with his "Breathing Earth") would open up fascinating research scenarios. Paraphrasing the judgement of Molnar (2007), "[NP] cannot have occurred and, therefore, did not occur", it would be more prudent to state that NPs can occur in another scheme and, therefore, could possibly occur, leaving to us the duty of checking whether enhanced periods of uplift occurred or not (without excluding other possible regional uplift not correlated to NPs). Yet another opening for research into unexplored areas.

The EE framework offers a possible explanation for the great asymmetry of the Earth, closely related to the previous solution for metamorphism. This involves the different angle of immersion of the Pacific distributions of intermediate and deep hypocentres in the Asian and American Wadati-Benioff zones, with a steep distribution in the west and gentler immersion, about $30^{\circ}$, below the
Americas. Many researchers (including many Italians) have been puzzled by this asymmetry and the literature on the subject is vast and always aimed at finding an external cause for the phenomenon, and specifically from outside the Earth (see references in Scalera, 2014). The first proposed cause is the tidal action of the Moon, and to a lesser extent of the Sun, on the outer layers of our planet, generating a small component of tangential force directed from East to West. The consequence would be a differential rotation of the lithosphere towards the west, which in turn, applying the simple law of composition of velocities, would influence the angle of immersion of the subduction plates towards the two opposite shores of the Pacific in two different ways (references in Scalera, 2014).

There are at least two major problems with this plate tectonics solution: i) the torsional moment resulting from the lunisolar action is considered insufficient to overcome the high viscosity of the Earth's mantle; ii) the hypothesis of a very thin low-viscosity layer acting as a functional decoupling for the "westward-drift" is negated by inability to observe one, and by the fact that seismic tomography indicates marked irregularities in the heights of radial mantle discontinuities, with significant regional ascents of the mantle that would intersect the hypothesised low viscosity layer, undulating it and making it impossible for the upper layers to rotate on the lower ones. This would be like affirming that two intermeshed cogs could rotate with independent direction and velocity.

The solution must therefore come from inside the planet and is found by re-evaluating the much neglected fictitious Coriolis force. The hypothesized slow tangential translation of the plates (speeds in order of magnitude $\mathrm{cm}$ / year) and the consequent imagined slow immersion of the lithosphere in subduction, causes proponents of plate tectonics to ignore the Coriolis force as insignificant. This is because at displacement rates over time of $\mathrm{cm} / \mathrm{year}$, the values of Coriolis force would be far too low to overcome the viscous resistance of the mantle. However, admitting that intermediate and deep earthquakes are expressions of impulsive extrusion activity of deep materials, and that the velocities of displacement are analogous to those detected for surface earthquakes (order of magnitude $\mathrm{m} /$ $\mathrm{sec}$ ) it is easily calculated that inertial forces would prevail by many orders of magnitude over viscous resistances (Scalera, 2014). These forces now become significant and determine a westward shift of any material impulsively pushed upwards from the terrestrial interior during deep earthquakes.

Finally, it is important to mention the expected enhanced phenomena by EE in the area of maximum expansion in the Nazca region and along the adjacent Andes mountain belt. An analysis of the Smithsonian Institution's catalogue data for the eruptions of Andean volcanoes from 1800 to 2010 suggests a causal relationship between eruptions and large earthquakes $(M>8.4)$, with an increase in eruption rates before major seismic events, and a periodicity of about 50 years between these volcano-seismic correlation events. A much longer series of data, containing future volcanoseismic events, need to be studied to arrive at a definitive conclusion, from the perspective of using this phenomenon by the Civil Protection services (Scalera, 2011, 2013) in prevention programs for natural disasters.

It is also observed that the volcano-seismic correlation events of 1960 and 2010 occurred ten years after five- 
year periods of almost total stagnation of the PM (the years 1945-1950 and 1995-2000). This stasis cannot be observed for the 1906 event due to the unreliability of PM astrogeodetic data collected before 1900 (Scalera, 2011, 2013). The possible correlation between these volcanoseismic events in South America and the PM Markowitz oscillation is another good reason to look for an integrated geodynamic explanation, with future lines of research on time series over subsequent centuries.

\section{CONCLUSIONS}

I have been involved in these issues for forty years, continuing even now when I am outside the institutions but still "enthusiastic" about the work, which, if conducted with integrity (one cannot say without errors), repays with the feeling of not having wasted a life. I can thus claim to be one of the "enthusiasts" cited in PS2 (page 179), but not in the intended derogatory sense. Many of these (and increasingly so) all over the world have had to fall back on their own enthusiasm because of rigid scientific institutions that filter appointments on the basis of loyalty to the mainstream. A case to point is the wanderings of our Italian-French Turin biologist Leon Croizat, "exiled" from the USA to South America, where he finally became established (Colacino \& Grehan, 2003).

Croizat was also defamed and defined a lunatic for practicing a science considered to be superseded. Instead he understood the limits and incompleteness of Darwinism and neo-Darwinism, which assumed only natural selection as the single important cause for biological evolution. Darwin himself was not rigid in his theoretical formulations, subsequently opening up to various causes that assisted natural selection (Barsanti, 2009) and as a young man he had practiced geology (Chiesura, 2002, 2014). Croizat instead proposed a combined evolution of organisms and geological processes, in which geology played the leading role over biology, but without dismissing any internal organic causes of speciation, while also assigning an appropriate role to natural selection (Croizat, $1958,1962)$. His vision was therefore more complete and founded on real facts rather than assumptions. With his panbiogeographic method he identified many disjointed circum-Pacific biogeographic distributions that were incompatible with Pangea and Wegener's theory (analogous cases in: Grehan, 2007; McCarthy, 2007). For this reason, the modern discipline he developed of panbiogeography does not exclude the possibility of terrestrial expansion, even though he was never an expansionist himself.

While Croizat did well in the end with his hard-won position, despite the ostracism of the establishment especially in the English-speaking world, many other dissenters have had to seek alivelihood elsewhere and have spent a lot of time achieving this that could have been better employment in fruitful study and research. Their results and ideas are therefore perhaps even more noble than any achieved under the umbrella of status by those who excluded them. Outsiders and amateurs are not conditioned by funding, careers, or cultural subjugation, making them more inclined to accept and affirm scientific truths. In my opinion, their presence in large numbers in certain fields at certain times is an index of a discipline that is still in a pre-paradigmatic phase, but that is also moving towards acceptance from the scientific community. The history of science today dedicates specific studies to enthusiasts, investigating their sometimes extraordinary contributions (Scalera, 2009a; see special issue of Gesnerous: Guillemain \& Richard, 2016; Le Vigouroux \& Gohau, 2016).

In Italy the situation was more amenable, probably thanks to greater historical awareness among those who guided the scientific institutions, allowing voices outside the chorus to develop their own ideas with sufficient freedom and support. These include the many who have worked here with us in all fields, from physics to biology, from geology to mathematics, in complete independence, like the teacher and colleague of Croizat, Daniele Rosa, and his student Giuseppe Colosi (Baccetti \& Omodeo, 1976; Luzzatto et al., 1977).

The unfounded accusations of pseudoscience (as demonstrated above) against working expansionists are a source of great pride for all defenders of EE when they discover that they have become targets for those who think they already know everything. The latter appear to feel threatened by changes in a science that is progressing very fast, perhaps foreseeing possible future implications that will require renunciations in fields like philosophy and religion. I believe the inadequacies of the criticisms made in PS1 and PS2 have been demonstrated and that the expanding Earth has been shown not to be an out-dated concept belonging to the historical-scientific contingencies of the past, but that it is instead a vibrant and fertile area of science projected towards the future.

The numerous lines of research initiated on the strength of EE and described briefly above certainly do not represent an exhaustive list. EE falls well within current ideas and experimental results, from which it will be able to draw ever more complete form and structure in coming decades. There is likely to be a convergence with modern panbiogeography, and major surprises as research develops on the deepest interior of the Earth, in synergy with the major experiments underway in fundamental physics. Developments in astronomy and astrophysics are also very promising, in particular the Gaia mission. Its name linking back to the Earth could be a good omen that, like other major experiments in physics, it will also have valuable repercussions for EE.

I hope this short paper will convince readers that it is not merely an issue of expansionists insisting they are right, but rather that the Earth itself is insisting we read the new geological, physical, geometric, geomorphological, seismological, chronological, geomagnetic, climatological, paleobiological, geothermal, volcanological, astrogeodetic data, and then interpret them in a more appropriate way. All this evidence taken together simply excludes the possibility of large-scale subductions, while strongly supporting the alternative explanation of Earth expansion. Too many factors point in the same direction for it to be overturned with tenuous criticism. The physiographic map of the seafloors by Heezen \& Tharp (1977) already represents a first simple indication of this reality.

I am confident that when all this interwoven evidence inevitably comes to be acknowledged, it will not induce adjustments to plate tectonics, but a radically new vision of the world. I am not a literal follower of the concepts of Thomas Kuhn (1996) although I admit the existence of "paradigms" and "opposed parties" in science. However, in 
other fields like evolution or the origin of hydrocarbons, a synthesis and coexistence between natural selection and Lamarkism is being achieved through evolutionary epigenetics, and between the biogenic and abiogenic origins of oil by recognizing coexistence of both processes, both developments that controvert Kuhn's vision. However, in the case of the plate tectonics paradigm and the concept of EE (not yet a paradigm and hopefully never one, instead remaining open science), what synthesis is possible? If large scale subduction is excluded by the permanence of the Pacific conformities, consequently also excluding the slow expansion model, what would remain of plate tectonics? What would remain without the compression mechanism derived from subduction for orogenesis? It would appear that the resulting shift in Earth science concepts, with a reinstatement on different foundations and renewed ties with other disciplines, would be too radical to hope for significant continuity.

Plate tectonics as a theory is currently being superseded, perhaps over long and unpredictable timescales, but there is new science on the horizon. This is partly thanks to the geological sciences being practiced on a small celestial body, our nearest neighbour on which we have walked, and from where we can expect further surprising discoveries for the construction of an image of the universe closer to the truth. An image that would be impossible to build without acknowledging and welcoming EE and generalized expansion of celestial bodies as a fundamental part of the evolution of the Universe.

\section{ELECTRONIC SUPPLEMENTARY MATERIALS}

More details on the cartographic experiments of Figs. 03, 04, and 05, as well as lists of the GPMDB data used, can be found in the Supplementary Materials which is available to authorised users.

\section{ACKNOWLEDGMENTS}

The management and editorial team of ROL allowed with foresight and steadfast guidance the publication of this reply on topics still considered controversial today. Gavin proofread my English with great patience. An enthusiastic patron of the expanding Earth who hides under the pseudonym Silvano Gioca covered the editorial expenses.

\section{REFERENCES}

Anderson D.L. (2009) - Energetics of the Earth and the Missing Heat Source Mystery. Technical Report: www.mantleplumes.org/ Energetics.html

Baccetti B. \& Omodeo P. (1976) - In memoria di Giuseppe Colosi (1892-1975), Italian Journal of Zoology, 43(3), 323-334.

Barsanti G. (2009) - Darwin: la sopravvivenza del più debole e il problema delle cosiddette razze umane (Darwin: the survival of the weakest and the problem of the so-called human races). In Italian. In: L. Calabi (ed.): Il futuro di Darwin - La specie. $2^{\text {nd }}$ session of the Baxter Lectures dell'Università di Pisa, UTET, Torino, 65-75.

Bell K., Castorina F., Lavecchia G., Rosatelli G. \& Stoppa F. (2004) - Is There a Mantle Plume Below Italy? Eos, Vol. 85, No. 50, 14 December 2004, pags. 541, 546-547.

Besse J. \& Courtillot V. (1991) - Revised and synthetic apparent polar wander paths of the African, Eurasian, North American and Indian plates, and true polar wander since 200 Myr. J. Geophys. Res., 96, 4029-4050.
Besse J. \& Courtillot V. (2002) - Apparent and true polar wander and the geometry of the geomagnetic field over the last $200 \mathrm{Myr}$. J. Geophys. Res., 107 (B11), 2300, https://doi.org/10.1029/2000JB000050

Bianco G. (2005) - Gli effetti del terremoto del sud-est asiatico sulla geodinamica globale (The effects of the Southeast Asian earthquake on global geodynamics). PowerPoint file of the seminar held at the Meeting "Il Terremoto-Maremoto nel Sud-Est Asiatico del 26 dicembre 2004". Accademia Nazionale dei Lincei, Roma January 25, 2005, http://www.fis.uniroma3.it/plastino/ seminars/terr_mar.html

Borexino collaboration (2017) - Borexino: geo-neutrino measurement at Gran Sasso, Italy. Annals of Geophysics, 60(1), S0114, 9 pp.

Cahill R.T. (2009) - Dynamical 3-Space: A Review. In Duffy \& Levy (eds.): Ether Spacetime and Cosmology: New Insights into a Key Physical Medium. Apeiron, 135-200.

Carey S.W. (1961) - Palaeomagnetic evidence relevant to a change in the Earth's radius (a reply to Cox \& Doell). Nature, 190(4770), 36-36.

Carminati E., Lustrino M., Cuffaro M. \& Doglioni C. (2010) - Tectonics, magmatism and geodynamics of Italy: What we know and what we imagine. Journal of the Virtual Explorer, Electronic Edition, 36, paper 9. In: Beltrando M., Peccerillo A., Mattei M., Conticelli S., Doglioni C. (eds.): The Geology of Italy: tectonics and life along plate margins. 1-58.

Chen Q. \& Yan W., Duan E. (2016) - Epigenetic inheritance of acquired traits through sperm RNAs and sperm RNA modifications. Nat Rev Genet., 17(12), 733-743.

Chiesura G. $(2002,2014)$ - Charles Darwin geologo. Hevelius Edizioni, Benevento, 207 pp. Second updated edition 2014, Società Geologica Italiana, Roma, 208 pp.

Chudinov Y.V. (1980) - Proiskhozhdeniye Al'piyskogo skladchatogo poyasa stochki zreniya gipotezy rasshireniya Zemli (Origin of the Alpine folding belt from the viewpoint of the Expanding Earth hypothesis). In Russian. In: Muratov M.V., Yanshin A.L. (eds.): Tectonics of the Mediterranean belt. Nauka Publ. (MS), 223-237.

Colacino C. \& Grehan J.R. (2003) - Ostracismo alle frontiere della biologia evoluzionistica: il caso Léon Croizat (Ostracism at the frontiers of evolutionary biology: the Léon Croizat case). In Italian. In: Capria M.M. (ed.) Scienza e Democrazia. Contributi al convegno internazionale "Science and Democracy", Napoli, Istituto Italiano per gli Studi Filosofici, 20-21 aprile 2001, Liguori Editore, 195-220.

Coltorti M. \& Ollier C.D. (1999) - The significance of high planation surfaces in the Andes of Ecuador. Geological Society of London Special Publication. 162, 239-253.

Consoli M. \& Pluchino A. (2015) - Il vuoto: un enigma tra fisica e metafisica (The vacuum: an enigma between physics and metaphysics). In Italian. Aracne Editrice, Roma, 172 pp.

Consoli M., Pluchino A., Rapisarda A. \& Tudisco S. (2014) - The vacuum as a form of turbulent fluid: Motivations, experiments, implications. Physica A, 394, 61-73.

Cox A. \& Doell R.R.(1961) - Palaeomagnetic evidence relevant to a change in the Earth's radius. Nature, 189(4758), 45-47.

Cox A. \& Doell R.R. (1961) - Palaeomagnetic evidence relevant to a change in the Earth's radius (a reply to Carey). Nature, 190(4770), 36-37.

Croizat L. (1958) - Panbiogeography, or an Introductory Synthesis of Zoogeography, Phytogeography and Geology, with notes on evolution, systematics, ecology, anthropology, 3 volumes, Caracas, Venezuela: published by the author, $2749 \mathrm{pp}$.

Croizat L. (1962) - Space, Time, Form: The Biological Synthesis. Caracas, Venezuela: published by the author, i-xix, $881 \mathrm{pp}$.

Crowley T.J. \& Zachos J.C. (2000) - Comparison of zonal temperature profiles for past warm time periods. In: Huber, B.T., MacLeod, K.G. and Wing, S.L. (eds.): Warm climates in Earth history. Cambridge University Press, Cambridge, 50-76.

Davidson J.K. (1994) - Earth expansion requires increase in mass. In: Barone, M. and Selleri, F. (eds.): Frontiers of Fundamental Physics. Plenum Press, New York, 295-300.

Degueldre C. \& Fiorina C. (2016) - The proto-Earth geo-reactor: Reassessing the hypotheses. Solid Earth Sciences, 1, 49-63.

De Paoli M. (1988) - L’Infinito, il Vuoto - Dialettica delle configurazioni dell'Infinito e del Vuoto nel pensiero occidentale (The Infinite, the Vacuum - Dialectic of the configurations of Infinity and the 
Vacuum in Western thought). In Italian. Schena Editore, Fasano, 168 pp.

Dirac P.A.M. (1937) - The Cosmological Constants. Nature, 139, 323 323.

Edwards M.R. (2016) - Indications from space geodesy, gravimetry and seismology for slow Earth expansion at present - comment on "The Earth expansion theory and its transition from scientific hypothesis to pseudoscientific belief" by Sudiro (2014), Hist. Geo Space. Sci., 7, 125-133.

Egyed L. (1960) - Some remarks on continental drift. Geofis. Pura Appl., 45, 115-116.

Egyed L. (1961) - Palaeomagnetism and the ancient radii of the Earth (discussion of paper by A. Cox and R. R. Doell). Nature, 190, n.4781, 1097-1098.

Einstein A. (1922) - Prospettive relativistiche dell'etere e della geometria (Relativistic perspectives of ether and geometry). Conference held at the University of Leiden on May 5, 1920. Casa Editrice Audace, Milano, 56 pp.

Engdahl E.R., van der Hilst R.D. \& Buland R.P. (1998) - Global teleseismic earthquake relocation with improved travel times and procedures for depth determination. Bulletin of the Seismological Society of America, 88, 722-743.

Fiorentini G., Lissia M. \& Mantovani F. (2007) - Geo-neutrinos and Earth's interior. arXiv:0707.3203v2 [physics.geo-ph]

Florindo F., Sagnotti L. \& Scalera G. (1994) - Using the ASCII version of the Global Paleomagnetic Database. EOS, 75/21, 236-237.

Frohlich C. (2006) - Deep Earthquakes. Cambridge University Press, Cambridge UK, 573 pp.

Furon R. (1935) - Les relations geologiques de I'Afrique et de l'Amerique du Sud (derive des continents et ponts continentaux), Mus. Natl. d'Hist. nat. Arch., 12, 211-215.

Furon R. (1941) - La paléogéographie, Essai sur l'évolution des continents et des oceans, Payot, Paris, 530 pp.

Gissis S.B. \& Jablonka E. (2011) - Transformations of Lamarkism - From Subtle Fluids to Molecular Biology. Vienna Series in Theoretical Biology, The MIT Press, Cambridge, Massachusetts, $457 \mathrm{pp}$.

Grehan J.R. (2007) - A Brief Look at Pacific Biogeography: The TransOceanic Travels of Microseris (Angiosperms: Asteraceae). In: M.C. Ebach \& R.S. Tangney (Eds.) Biogeography in a changing world. Systematics Association spec. vol. no. 70, CRC Press, London, 83-94.

Guillemain H. \& Richard N. (2016) - Introduction. Towards a Contemporary Historiography of Amateurs in Science (18th-20th Century). Gesnerus, 73(2), 201-237.

Heezen B.C. \& Tharp M. (1977) - World Ocean Floor (a map). U.S. Navy Office of Naval Research, Washington, DC.

Herndon J. (1993) - Feasibility of a nuclear fission reactor at the center of the Earth as the energy source for the geomagnetic field. J. Geomagnet. Geoelectr. 45, 423-437.

Hilgenberg O.C. (1974) - Vom wachsenden Erdball (The Expanding Earth). Giessmann \& Bartsch, Berlin, 56 pp.

Hilgenberg O.C. (1974) - Geotektonik, neuartig gesehen (Geotectonics, seen in a new way). Geotektonische Forshungen, 45(1-2), 194 pp.

Hilgenberg O.C. (1967) - Why Earth expansion? Extended translation of the talk held to the Thecnical University Berlin on February 7 1967. Published by the author, Berlin, 16 pp. Hilgenberg O.C. (1974)

Hossenfelder S. (2018) - Lost in Math: How Beauty Leads Physics Astray. Basic Books, New York, 291 pp.

Hurrell S. (2012) - Ancient Life's Gravity and its Implications for the expanding Earth. In: G. Scalera, E. Boschi and S. Cwojdziński (eds.) The Earth Expansion Evidence - A Challenge for Geology, Geophysics and Astronomy. Selected Contributions to the Interdisciplinary Workshop of the 37th International School of Geophysics EMFCSC, Erice (4-9 October 2011), Aracne Editrice, Roma, 307-325.

Jablonka E. \& Lamb M.J. (1989) - The Inheritance of Acquired Epigenetic Variations. J. theor. Biol., 139, 69-83; reprinted in: International Journal of Epidemiology, 2015, 1094-1103.

Khan Z.A. \& Tewari R.C. (2017) - Indus-Yarlung-Tsangpo Suture Zone Concept - A Second Opinion. Journal of Tethys, 5(3), 218-239.
Kostro L. (2000) - Einstein and the ether. Apeiron, Montreal, 242 pp.; Italian edition: (2001) - Einstein e l'etere. Edizioni Dedalo, Bari, 317 pp.

Kragh H.S. (2016) - Varying Gravity - Dirac's Legacy in Cosmology and Geophysics. Science Networks Historical Studies vol.54, Birkhäuser, Heidelberg, 185 pp.

Kragh H.S. \& Overduin J.M. (2014) - The Weight of the Vacuum - A Scientific History of Dark Energy. Springer, Heidelberg, 113 pp.

Kuhn T.S. (1996) - The structure of scientific revolutions. 3rd ed., University of Chicago Press, xiv - 212 pp.

Lambert D. (2016) - The Atom of the Universe - The Life and Work of Georges Lemaître. Preface by P.J.E. Peebles. Copernicus Center Press, Kraków, 464 + XIX pp.

Larson R.L., Pitman III W.C., Golovchenkso X., Cande S.C., Dewey J.F., Haxby W.F. \& La Brecque J.L. (map compilers) (1985) The bedrock geology of the world. Freeman and Co. Inc., New York.

Lerner E. (1992) - The Big Bang Never Happened: A Startling Refutation of the Dominant Theory of the Origin of the Universe. Simon \& Schuster, New York, 496 pp. Italian Translation, Dedalo, Bari, 1994, 490 pp.

Le Vigouroux P. \& Gohau G. (2016) - De l'amateurisme en géologie: la réception française de la théorie de la dérive des continents (19201950). Gesnerus, 73(2), 337-359.

Lima-de-Faria A. (1988) - Evolution Without Selection: Form and Function by Autoevolution. Elsevier, 271 pp.; Italian edition by Serafini S., \& Sermonti G.: (2006) Evoluzione senza selezione. Autoevoluzione di forma e funzione. Nova Scripta, Genova, 504 pp.

Lock J. \& McElhinny M.W. (1991) - The Global Paleomagnetic Database: Design, installation, and use with ORACLE. Surv. Geophys., 12, 317-491.

López-Corredoira M. (2019) - Observational Cosmology: caveats and open questions in the standard model. arXiv:astro-ph/0310214v2

Lustrino M., Duggen S., Rosenberg C.L. (2011) - The Central-Western Mediterranean: Anomalous igneous activity in an anomalous collisional tectonic setting. Earth Science Reviews, 104, 1-40.

Luzzatto M., Paestrini C. \& Passerin D’Entrèves P. (1997) - L'opera dimenticata di Daniele Rosa (The forgotten work of Daniele Rosa). In Italian. Accad. Sci. Torino. Mem. Sci. Fis., vol. 21, 3-48.

Mancktelow N.S. (1995) - Nonlithostatic pressure during sediment subduction and the development and exhumation of high pressure metamorphic rocks. Journal of Geophysical Research, $100(\mathrm{Bl}), 571-582$

Mancktelow N.S. (2008) - Tectonic pressure: Theoretical concepts and modelled examples. Lithos, 103(1-2), 149-177.

Mardfar R.A. (2012) - Relationship Between Gravity and Bio-Evolution - The Increasing Gravity Theory. In: G. Scalera, E. Boschi and S. Cwojdziński (eds.) The Earth Expansion Evidence - A Challenge for Geology, Geophysics and Astronomy. Selected Contributions to the Interdisciplinary Workshop of the 37th International School of Geophysics EMFCSC, Erice (4-9 October 2011), Aracne Editrice, Roma, 327-341.

Maxlow J. (2018) - Beyond plate tectonics - Unsettling settled science. Aracne Editrice, Roma, 492 pp.

McCarthy D. (2003) - The trans-Pacific zipper effect: disjunct sister taxa and matching geological outlines that link the Pacific margins, J. Biogeogr., 30, 1545-1561.

McCarthy D. (2005) - Biogeographical and geological evidence for a smaller, completely-enclosed Pacific Basin in the Late Cretaceous, J. Biogeogr., 32, 2161-2177.

McCarthy D., Ebach M.C., Morrone J.J. \& Parenti L.R. (2007) - An alternative Gondwana: Biota links South America, New Zealand and Australia. Biogeografía, 2 (July), 2-12.

McElhinny M.W. \& McFadden P.L. (2000) - Paleomagnetism, continents and oceans. Academic Press, New York, 380 pp.

Molnar P. (2007) - An Examination of Evidence Used to Infer Late Cenozoic "Uplift" of Mountain Belts and Other High Terrain: What Scientific Question Does Such Evidence Pose? Journal Geological Society of India, Vol. 70, September, 395-410.

Moretti A., Guerra I. (1997) - Tettonica dal Messiniano ad oggi in Calabria: Implicazioni sulla geodinamica del sistema TirrenoArco Calabro. Boll. Soc. Geol. It., 116, 125-142. 
Morgan J.W. (1968) - Rises, Trenches, Great Faults, and Crustal Blocks. - Journal of Geophysical Research, 73(6), 1959-1982.

Müller R.D., Sdrolias M., Gaina C. \& Roest W.R. (2008) - Age, spreading rates, and spreading asymmetry of the world's ocean crust. Geochemistry geophysics geosystems (G3), 9, Q04006, https://doi.org/10.1029/2007GC001743

Ollier C.D. \& Pain C.F. (2000) - The Origin of Mountains. Routledge, London, $345 \mathrm{pp}$.

Ollier C.D. \& Pain C.F. (2019) - Neotectonic mountain uplift and geomorphology, Геоморфология (Geomorphology), 4, 3-26.

Pisarevsky S. (2005) - New edition of the Global Paleomagnetic Database. EOS, 86(17), 170.

Scalera G. (1988) - Relazioni tra teorie geofisiche e cosmologiche del 900 (Relationships between geophysical and cosmological theories of the twentieth century). In Italian. Atti della sezione Storia della Scienza del congresso SIF 1987, 473-484.

Scalera G. (1990) - The significance of a new class of shape similarities for global tectonic teories. Atti $8^{\circ}$ Convegno Annuale G.N.G.T.S. Roma 7-9 novembre 1989, Esagrafica, Roma, 635-639.

Scalera G. (1991) - Paleopoli cambriani, simmetrie e paleopoli pacifici: alcune inconsistenze con la plate tectonics (Cambrian paleopoles, symmetries and Pacific paleopoles: some inconsistencies with plate tectonics). In Italian. Atti del $9^{\circ}$ Convegno Annuale G.N.G.T.S., Roma 13-15 novembre 1990, Esagrafica, Roma, 757775.

Scalera G. (1993) - Non-chaotic emplacements of trench-arc zones in the Pacific Hemisphere. Annali di Geofisica, 36(5-6), 47-53.

Scalera G. (1995) - Ricostruzioni paleogeografiche e cinematica delle placche su una Terra in espansione (Paleogeographic reconstructions and plate kinematics of an expanding Earth). In Italian. Atti del $13^{\circ}$ Convegno Annuale del GNGTS, Roma 28-30 novembre 1994, Esagrafica, Roma, 257-262. VERIFICA

Scalera G. (1995) - Terra in espansione (Expanding Earth). Entry for the Enciclopedia delle Scienze Fisiche, vol.VI, Istituto per la Enciclopedia Italiana Treccani, Roma, p228-231.

Scalera G. (2001) - The Global paleogeographical reconstruction of the Triassic in the Earth's dilatation framework and the paleoposition of India. Annali di Geofisica, 44(1), 13-32.

Scalera G. (2002) - Possible relations among expanding Earth, TPW and Polar Motion. In: Maslov L (ed.) Proceedings Int Symposium on New Concepts in Global Tectonics, held in May 2002 in La Junta, Colorado, Otero Junior College Press, La Junta, 37-50.

Scalera G. (2003) - The expanding Earth: a sound idea for the new millennium. In: G. Scalera and K.-H. Jacob (eds.): Why Expanding Earth? - A book in Honour of Ott Christoph Hilgenberg. Proceedings of the 3rd Lautenthaler Montanistisches Colloquium, Mining Industry Museum, Lautenthal (Germany) May 26, 2001. (INGV Publication, Rome), 181-232.

Scalera G. (2005) - A new interpretation of the Mediterranean arcs: Mantle wedge intrusion instead of subduction. Boll. Società Geologica Italiana, Volume Speciale, no. 5, 129-147.

Scalera G. (2007a) - Fossils, frogs, floating islands and expanding Earth in changing-radius cartography - A comment to a discussion on Journal of Biogeography. Annals of Geophysics, 50(6), 789-798.

Scalera G. (2007b) - A new model of orogenic evolution. Rendiconti Soc. Geol. It., Nuova Serie, 5, 214-218.

Scalera G. (2008a) - The long dream of the Mediterranean subduction. Rendiconti Online Società Geologica Italiana, 3, 710-711.

Scalera G. (2008b) - Quale geodinamica per lo Stretto di Messina? (What geodynamics for the Strait of Messina?). In Italian. Extended abstracts of the Meeting "1908-2008, Scienza e Società a Cento Anni dal Grande Terremoto (1908-2008, Science and Society One Hundred Years after the Great Earthquake)" held in Reggio Calabria, 10-12 December 2008, Miscellanea INGV, N.03, 107-108.

Scalera G. (2009a) - The Proterozoic Position of India in an Expanding Earth Paleogeography. In Singh V.K., Chandra R. (eds.): Abstracts Book 2nd International Conference on Precambrian Continental Growth and Tectonism (PCGT 2009) held at the Institute of Earth Sciences, Bundelkhand University, Jhansi, India, 24-28 February 2009, Excel India Publishers, New Delhi, 47-49.
Scalera G. (2009b) - Roberto Mantovani (1854-1933) and his ideas on the expanding Earth, as revealed by his correspondence and manuscripts. Annals of Geophysics, 52(6), 615-648.

Scalera G. (2010) - Earthquakes, phase changes, fold belts: from Apennines to a global perspective. GeoActa, Spec. Publ. n.3, "Geology of the Adriatic area", 25-43.

Scalera G. (2011) - Roots of modern geodynamical views in Schiaparelli's thought - The volcano-seismic correlation events on the Andes. Memorie Società Astronomica Italiana, Vol. 82, 377-384.

Scalera G. (2012a) - Is plate tectonics a Tychonian compromise? Z. geol. Wiss., 40(1), 19-34.

Scalera G. (2012b) - Distensional Mediterranean and World Orogens - Their Possible Bearing to Mega-Dykes Active Rising. In: G. Scalera, E. Boschi and S. Cwojdziński (eds.) The Earth Expansion Evidence - A Challenge for Geology, Geophysics and Astronomy. Selected Contributions to the Interdisciplinary Workshop of the 37th International School of Geophysics EMFCSC, Erice (4-9 October 2011), Aracne Editrice, Roma, 115-160.

Scalera G. (2014) - Cause of East-West Earth asymmetry. arXiv:1501.07213 [physics. geo-ph]. 9 pp.

Scalera G. (2015) - Sea Level Enigmatic Rising - New Perspectives from an Expanding Globe - arXiv preprint arXiv:1503.02731, 2015 - arxiv.org

Scalera G. (2018) - Sequenza di mappe paleogeografiche del Tardo Triassico assistite dal GPMDB (Sequence of paleogeographic maps of the Late Triassic period assisted by the GPMDB). In Italian. Atti del Convegno annuale GNGTS, Bologna 19-21 november 2018, 217-222. (english translation on Research Gate)

Scalera G. \& Braun T. (2018) - Ott Christoph Hilgenberg in twentieth-century geophysics. In: G. Scalera and K.-H. Jacob (eds.): Why Expanding Earth? - A book in Honour of Ott Christoph Hilgenberg. Proceedings of the 3rd Lautenthaler Montanistisches Colloquium, Mining Industry Museum, Lautenthal (Germany) May 26, 2001. (INGV Publication, Rome), 25-41.

Scrocca D., Carminati E., Doglioni C. \& Procaccianti D. (2012) Tyrrhenian Sea. In: Roberts D.G., Bally A.W. (eds.): Regional Geology and Tectonics: Phanerozoic Passive Margins, Cratonic Basins and Global Tectonic Maps. Volume 1C, Elsevier, Amsterdam, 473-485.

Selleri F. (2011) - La relatività debole. La fisica dello spazio e del tempo senza paradossi. Book Time, Collana Melquiades, Milano, 278 pp. (Posthumous English translation 2014, Barone M. (ed.): Weak Relativity. Kostarakis, Petroupoli, Greece. 274 pp.)

Shen W.-B., Sun R., Chen W., Zhang Z., Li J., Han J. \& Ding H. (2011) - The expanding Earth at present: evidence from temporal gravity field and space-geodetic data, Ann. Geophys.Italy 54, 436-453, https:// doi.org/10.4401/ag-4951

Shen W.-B., Shen Z.-Y., Sun R. \& Barkin Y. (2015) - Evidences of the expanding Earth from space-geodetic data over solid land and sea level rise in recent two decades, Geod. Geodyn, 10, 1-5, https://doi.org/10.1016/j.geog.2015.05.006

Shields O. (1979) - Evidence for initial opening of the Pacific ocean in the Jurassic Palaeogeography, Palaeoclimatology, Palaeoecology, 26, 181-220.

Shimizu I. (2017) - KamLAND: geo-neutrino measurement in Japan. Annals of Geophysics, 60(1), S0113, 4 pp.

Soares D. (2018) - The age of the universe, the Hubble constant, the accelerated expansion and the Hubble effect. arXiv:0908.1864v8 [physics.gen-ph]

Strutinski C. (2016) - The Lilliput Effect - a response of life to increasing gravity? Published online: June 2016, 10 pp.

Sudiro P. (2014) - The Earth expansion theory and its transition from scientific hypothesis to pseudoscientific belief. Hist. Geo Space. Sci., 5, 135-148.

Sudiro P. (2019) - Palaeomagnetism and the debate on the size of the Earth. Rend. Online Soc. Geol. It., Vol. 47, 179-184, 2 figs. (https://doi.org/10.3301/ROL.2019.29)

Sumner T. (2015) - Mystery at the Center of the Earth. Science News, Sept. 19, 18-21. 
Tonelli G. (2019) - From LHC to FCC (in Italian with English abstract). Il Nuovo Saggiatore - Bollettino della SIF, Anno 35 , N. $5-6,17-26$

Veikkolainen T.H., Biggin A.J., Pesonen L.J., Evans D.A.D. \& Jarboe N.A., (2017) - Advancing Precambrian palaeomagnetism with the PALEOMAGIA and PINT ${ }_{\text {OPI }}$ databases. Scientific Data, 4, 170068, https://doi.org/10.1038/sdata.2017.68

Vogel K. (1984) - Beitrage zur Frage der Expansion der Erde auf der Grundlage von Globenmodellen (The question of expansion of the Earth based on global models) (in German). Zeitschrif für Geologische Wissenschaften, 12(5), 563-573. Translated and reprinted in the Selected Contributions to the Interdisciplinary Workshop of the 37th International School of Geophysics EMFCSC, Erice (4-9 October 2011), Aracne Editrice, Roma (2012), 161-170.

Volovik G.E. (2001) - Superfluid analogies of cosmological phenomena. Phys. Rep. 351, 195-199.

Wegener A. (1912) - Die Entstehung der Kontinente. Petermanns Geog. Mitteilungen, 58, 185-195, 253-256, 305-309.

Wegener A. (1929) - Die Entstehung der Kontinente und Ozeane. Fiedr. Vieweg \& Sohn. Braunschweig. 4a ed. Italian translation by Clara Giua, Boringhieri, Torino, 1976, 313 pp.

Wezel F.-C. (1988) - Earth structural patterns and rhythmic tectonism. In: Wezel F.-C. (ed.): The Origin and Evolution of Arcs, Tectonophysics, 146(1-4), 1-45.
Wezel F.-C. (1992) - Global change: shear dominated geotectonics modulated by rhytmic Earth pulsations. In: Chatterjee V.S. and Hotton N. III (eds.): New Concepts in Global Tectonics. Texas Tech University Press, Lubbock, 421-439.

Wilczek F. (2008) - The Lightness of Being: Mass, Ether, and the Unification of Forces. Basic Books (AZ), 270 pp. Italian translation (2009) - La leggerezza dell'essere. La massa, l'etere e l'unificazione delle forze. Einaudi, Torino, $279 \mathrm{pp}$.

Xu C., Yu X. \& Wei D. (2019) - Implicit expansion rate of the Earth in global plate motions. Geodesy and Geodynamics, 10(3), 228234.

Xu C. \& Sun W. (2014) - Earthquake-origin expansion of the Earth inferred from a spherical-Earth elastic dislocation theory, Geophys. J. Int. 199(2014) 1655-1661.

Xu C., Wei D. \& Sun W. (2016) - Contribution of coseismic deformations on the current expansion of the Earth, J. Geodyn. 99(2016) 10-15. https://doi.org/10.1016/j. jog.2016.05.001

Yarkovsky I.O. (1888) - Hypothèse cinétique de la gravitation universelle en connexion avec la formation des éléments chimiques (Kinetic hypothesis of universal gravitation in connection with the formation of chemical elements). In French. Published by the author in Moscow. 139 pp. 